\title{
Mechanistic Insights into the Role of Val-75 of HIV-1 Reverse Transcriptase in Misinsertion and Mispair Extension Fidelity of DNA Synthesis
}

\author{
Tania Matamoros, ${ }^{1}$ Baek Kim ${ }^{2}$ and Luis Menéndez-Arias ${ }^{1 *}$ \\ ${ }^{1}$ Centro de Biología Molecular "Severo Ochoa", Consejo Superior de Investigaciones \\ Científicas - Universidad Autónoma de Madrid, 28049 Madrid, Spain \\ ${ }^{2}$ Department of Microbiology and Immunology, University of Rochester Medical Center, \\ Rochester, NY 14642, U.S.A.
}

Running title: Fidelity of Val-75 mutants of HIV-1 RT

* Corresponding author. E-mail address of the corresponding author: 1menendez@cbm.uam.es

October 31 st, 2007 


\begin{abstract}
The side-chain of Val-75 stabilizes the fingers subdomain of the human immunodeficiency virus type 1 (HIV-1) reverse transcriptase (RT), while its peptide backbone interacts with the single-stranded DNA template (at nucleotide +1) and with the peptide backbone of GIn-151. Specific DNA polymerase activities of mutant RTs bearing amino acid substitutions at position 75 (i.e. V75A, V75F, V75I, V75L, V75M, V75S and V75T) were relatively high. Primer extension experiments carried out in the absence of one dNTP suggested that mutations did not affect the accuracy of the RT, except for V75A, V75F, V75I, and in a lesser extent V75T. The fidelity of RTs bearing mutations V75F and V75I increased 1.8- and 3-fold, respectively, as measured by the M13 lacZ $\alpha$ forward mutation assay, while V75A showed 1.4-fold decreased accuracy. Steady- and pre-steady-state kinetics demonstrated that the increased fidelity of V75I and V75F was related to their decreased ability to extend mismatched template-primers, while misincorporation efficiencies were not significantly affected by mutations. The increased mispair extension fidelity of mutant V75I RT could be attributed to the nucleotide affinity loss, observed in reactions with mismatched template-primers. Altogether, these data suggest that Val-75 interactions with the $5^{\prime}$ template overhang are important determinants of fidelity.
\end{abstract}

Keywords: HIV, DNA polymerase, fidelity, reverse transcriptase, drug resistance 


\section{Introduction}

Human immunodeficiency virus type 1 (HIV-1) reverse transcriptase (RT) converts the viral genomic RNA to a double-stranded DNA (dsDNA) intermediate which integrates into the host genome. RT is a multifunctional enzyme, possessing RNA- and DNA-dependent DNA polymerase, RNase $\mathrm{H}$, strand transfer and strand displacement activities. ${ }^{1}$ The HIV-1 RT is a heterodimeric enzyme composed of two subunits of 66 and $51 \mathrm{kDa}$ respectively, with subdomains termed fingers, thumb, palm and connection in both subunits and an RNase $\mathrm{H}$ domain in the larger subunit only. ${ }^{2,3}$ The DNA polymerase active site resides within the palm subdomain of the larger subunit (p66), which contains the essential catalytic aspartic acid residues 110, 185 and 186. ${ }^{4,5}$ Other residues in their vicinity, such as Lys-65, Arg-72, Asp-113, Ala-114, Tyr-115 and Gln-151 are involved in the interactions with the incoming dNTP, while Leu-74, Pro-157, Phe-160, Tyr-183 and Met-184 could indirectly affect dNTP binding. ${ }^{3}$

Reverse transcription is error prone and contributes to the high genetic variability of retroviruses. Mutation rates in a single cycle of retrotranscription are in the range of $10^{-4}-10^{-5}$ misincorporations per nucleotide. One of the consequences of the high mutation rates has been the emergence of drug resistant HIV variants. Polymerization errors can be generated either by misinsertion of an incorrect nucleotide followed by mispair extension, or by transient primer slippage. ${ }^{6}$ Mutational studies have shown that molecular determinants of nucleotide specificity and fidelity of DNA synthesis map within the HIV-1 RT p66 subunit, mostly in the vicinity of the dNTP binding site. ${ }^{7,8}$ Thus, nonconservative amino acid changes affecting Tyr-115, as well as the substitutions of Ala for Arg72 or Met184 were shown to reduce the accuracy of the viral RT. ${ }^{9-13}$ On the other hand, several mutations affecting residues that interact with the incoming nucleotide (e.g. at positions 65,151 and 184 ) increase the accuracy of the viral RT. ${ }^{10,14-17}$ 
Structural determinants of RT fidelity are not restricted to residues close to the polymerase active site. Several amino acid substitutions affecting interactions with nucleotides 1 and -2 of the primer (e.g. F227A, M230I), ${ }^{16,18-20}$ or interactions with the template grip (e.g. E89K and other amino acid changes at this position), ${ }^{21}$ as well as amino acid changes involving residues that contact the minor groove of the template-primer (e.g. G262A, W266A) were shown to decrease the accuracy of the HIV $-1 \mathrm{RT} .^{22}$ In addition, mutations in the primer grip of the RNase H domain could also influence fidelity, as demonstrated for the murine leukaemia virus $\mathrm{RT}^{23}$

Another set of residues that contributes to fidelity of reverse transcription includes amino acids that interact with $5^{\prime}$ single-stranded template overhang. According to the crystal structure of the ternary complex of HIV-1 RT $\bullet$ DNA/DNA $\bullet$ dTTP, ${ }^{3}$ residues 24-27, 30 and 61-63 pack against template nucleobases +2 and +3 , with Trp-24, Pro-25, Lys-30, Phe-61 and Ile-63 contributing the largest contact surface. Residues $72,74-78$ and 81 interact with the template nucleotide +1 , with Leu-74 and Arg-78 making the largest number of contacts with the nucleotide. Several mutants affecting interactions with the single-stranded template (F61A, L74V, D76I, D76R, D76V and R78A) were found to increase fidelity of DNA synthesis, based on determinations of steady-state kinetic parameters or mutant frequencies obtained with the M13 lacZ $\alpha$ forward mutation assay. ${ }^{24-28}$ However, most of the residues interacting with the $5^{\prime}$ template overhang are highly conserved among HIV-1 isolates (http://hivdb.stanford.edu/).

Drug resistance-related mutations at positions 62 (i.e. A62V), 74 (i.e. L74I and L74V) and 77 (i.e. F77L) are likely to emerge after treatment with nucleoside analogue RT inhibitors, although codon 75 shows the highest variability under drug pressure. ${ }^{29,30} \mathrm{~A} 62 \mathrm{~V}, \mathrm{~V} 75 \mathrm{I}, \mathrm{F} 77 \mathrm{~L}$ and F116Y are secondary mutations that together with Q151M confer resistance to multiple nucleoside analogues. ${ }^{31,32}$ V75T was related to low-level resistance to stavudine and other dideoxynucleosides $^{33}$ and V75L has been observed as a secondary mutation in HIV-1 variants 
resistant to quinoxaline nonnucleoside RT inhibitors. ${ }^{34}$ Other amino acid substitutions at this position (e.g. V75A, V75M and V75S) are also frequently found in patients undergoing therapy with RT inhibitors. ${ }^{30}$

In this work, we have obtained a series of mutant RTs with substitutions at position 75 in order to define the role of Val-75 in nucleotide specificity and fidelity of DNA synthesis. Mutant RTs with altered fidelity were identified, and kinetic parameters for nucleotide incorporation were determined under steady-state and pre-steady-state conditions. The results of misinsertion and mispair extension fidelity assays led to the identification of V75I as a substitution increasing the accuracy of the viral RT. Those data were consistent with the results obtained from assays based on the inactivation of the lacZ gene in bacteriophage M13mp2, and support the role of the $5^{\prime}$ single-stranded template as an important determinant of fidelity in HIV-1 RT.

\section{Results}

\section{Effect of amino acid substitutions on DNA polymerase activity}

The analysis of published crystal structures of HIV-1 RT reveals that Val-75 is located at the base of the fingers subdomain, more than $16 \AA$ away from the catalytic triad of the DNA polymerase active site. In the ternary complex of HIV-1 RT•DNA/DNA $\bullet$ dTTP, ${ }^{3}$ the distances between the $\mathrm{C} \alpha$ atom of Val-75 and the C $\alpha$ atoms of Asp-110, Asp-185 and Asp-186 are in the range of $19.8-22.7 \AA$. The side-chain of Val-75 is directed towards the hydrophobic core of the helices of the fingers subdomain, interacting with Val-60, Lys-73, Phe-77, and Tyr-146. ${ }^{3,35}$ The peptide backbone of Val-75 contacts the single-stranded template, through interactions between its $-\mathrm{CO}-$ group and the nucleotide at position +1 , while its $-\mathrm{NH}-$ group interacts with the peptide backbone of Gln-151. These observations suggest that amino acid substitutions 
affecting the side-chain of Val-75 would influence the topology of the RT C $\alpha$ backbone interacting with the $5^{\prime}$ template overhang, while having an effect on nucleotide selectivity.

Mutant RTs containing Ala, Phe, Ile, Leu, Met, Ser or Thr instead of Val-75 were obtained as p66/p51 heterodimers and their DNA-dependent DNA polymerase activity was determined by using a 47/25-mer heteropolymeric template-primer and dTTP, under steady-state conditions. As shown in Table 1, the introduced mutations produced moderate reductions in the catalytic efficiencies of nucleotide incorporation (measured as $k_{\text {cat }} / K_{\mathrm{m}}$ ), in comparison with the wild-type enzyme. While $k_{\text {cat }}$ values were similar for all of the mutants tested, differences in the catalytic efficiencies resulted from variations in the apparent $K_{\mathrm{m}}$ values, which were 2- to 3.8fold higher for mutant RTs than for the wild-type enzyme.

\section{Primer extension assays using deoxynucleotide templates and biased dNTP pools}

An initial assessment of the fidelity of mutant HIV-1 RTs was obtained by using an assay that monitors primer extension in the absence of one dNTP complementary to template nucleotides. Under these conditions, the elongation of the primer past a template nucleotide complementary to the excluded dNTP requires the insertion of an incorrect nucleotide and further extension of the generated mismatch primer. The results obtained using template-primer D2-47/PG5-25 are given in Figure 1. Full primer extensions were obtained with mutant and wild-type RTs when all required dNTPs were present in the reaction. Extension efficiencies were similar for the wild-type enzyme and for mutants V75L, V75M and V75S in all reactions. However, different band patterns were observed with mutants V75A, V75F, V75I and V75T. In the absence of dATP, the amount of fully extended primers accumulated in reactions catalyzed by V75A RT appears to be larger than in reactions catalyzed by the wild-type RT (Figure 1), particularly after long incubation times (for example, compare the intensities of the corresponding smears with those of bands at position +7 for mutant and wild-type RTs). In 
contrast, the products generated by V75F, V75I and V75T under those conditions were shorter. In comparison with the wild-type RT, there was a slower accumulation of fully extended products in reactions catalyzed by V75F (see arrows in Figure 1). This effect was also observed with mutants V75I and V75T, although in this case the most significant differences between mutants and wild-type RT were detected in reactions incubated during 5 or $15 \mathrm{~min}$, by comparing the relative intensities of bands +4 and +7 . Taken together, these results were taken as preliminary evidence suggesting that V75F, V75I and V75T RTs were more faithful than the wild-type enzyme, while V75A conferred reduced fidelity of DNA synthesis.

\section{Steady-state fidelity assays}

Misinsertion and mispair extension fidelity assays were used to estimate the accuracy of DNA polymerization catalyzed by the wild-type RT and mutants V75A, V75F and V75I. Steady-state kinetic parameters for the incorporation of nucleotides at the $3^{\prime}$ end of the primer were obtained with the heteropolymeric template-primer D2-47/PG5-25. Misinsertion fidelity assays involved kinetics measurements for the incorporation of a correct $(\mathrm{T})$ or an incorrect (A, $\mathrm{C}$ or G) nucleotide at the 3 'end of the primer, and the kinetic parameters, $k_{\text {cat }}$ and $K_{\mathrm{m}}$, are given in Table 2. All tested RTs misinserted dCTP and dGTP with the highest efficiency, whereas there was hardly any extension in the presence of dATP. Misinsertion ratios determined as the ratio of the catalytic efficiencies of incorporation of an incorrect dNTP relative to the correct dTTP were in the range from $3.1 \times 10^{-5}$ to 1.8 to $10^{-4}$. In general, these values were somewhat higher for the mutants than for the wild-type RT, although the largest differences were obtained with the mutant V75A, which showed a 5.8-fold higher misinsertion efficiency of dCTP incorporation, in comparison with the wild-type enzyme.

The kinetics of mispair extension were studied for correctly matched base pairs (A:T) and for mismatches A:C, A:G and A:A, using the template-primer D2-47/PG5-25 and its 
corresponding derivatives having primers PG5-25C, PG5-25G and PG5-25A, respectively. In all cases, we measured the incorporation of a correct $\mathrm{T}$ opposite $\mathrm{A}$ at the $3^{\prime}$ end of the primer. The results are shown in Table 3. Wild-type RT and the mutant V75A showed relatively small differences in their catalytic constants, although extension efficiencies of A:G and A:A mispairs were around 2-3 times higher for the mutant than for the wild-type enzyme. These data were in agreement with the lower fidelity displayed by V75A in misincorporation assays. In contrast, mutants V75I and V75F showed mismatch extension ratios that were around 3 to 5 times smaller than those obtained with the wild-type RT. These effects were observed with all three mispairs tested, and could be largely attributed to the larger increases in the apparent $K_{\mathrm{m}}$ values obtained in dTTP incorporation reactions of mismatched template-primers (Table 3).

\section{Pre-steady-state kinetic analysis of correct and incorrect nucleotide incorporation on matched template-primers}

Under the steady-state conditions used $K_{\mathrm{m}}=K_{\mathrm{d}}\left(k_{\mathrm{off}} / k_{\mathrm{pol}}\right) .{ }^{36}$ Therefore, the steady-state parameters reported above do not allow for the precise determination of either the $K_{\mathrm{d}}$ for the incoming dNTP, nor the rate constant of nucleotide incorporation, $k_{\mathrm{pol}}$, whose values have to be obtained from pre-steady-state kinetic experiments. Representative pre-steady-state burst experiments for the incorporation of a correct nucleotide (dTTP) on the DNA-DNA templateprimer 31T/21P, by the wild-type RT are shown in Figure 2 (a), left panel. The rate of nucleotide incorporation $\left(k_{\mathrm{obs}}\right)$ was determined from burst experiments carried out in the presence of different concentrations of dNTP. The biphasic nature of the burst indicates that rate-limiting step of the catalytic cycle occurs after chemistry. The exponential bursts showed a fast phase with rates of $3-11 \mathrm{~s}^{-1}$, and a slow phase (i.e. steady-state) with rates as high as 0.089 $\mathrm{s}^{-1}$, consistent with the $k_{\text {cat }}$ values reported in Table 1 . By analyzing the dependence of the reaction rate $\left(k_{\mathrm{obs}}\right)$ on dNTP concentration, we obtained a measure of both the maximum rate of 
dNTP incorporation $\left(k_{\mathrm{pol}}\right)$ and the dNTP binding affinity $\left(K_{\mathrm{d}}\right)$ after fitting the data to a hyperbolic curve (Figure 2 (b), left panel). Similar experiments were also carried out with the mutant enzymes and the dTTP concentration dependence plots are shown in Figure 2 (c), left. The pre-steady-state kinetic parameters of nucleotide incorporation, $k_{\mathrm{pol}}$ and $K_{\mathrm{d}}$, are given in Table 4. Catalytic efficiencies of correct nucleotide incorporation are similar for all RTs, except mutant $\mathrm{V} 75 \mathrm{~F}$, whose $k_{\mathrm{pol}} / K_{\mathrm{d}}$ value is lower, due to decreased $k_{\mathrm{pol}}$ and increased $K_{\mathrm{d}}$ in comparison with the wild-type enzyme.

The kinetics of misincorporation of dCTP and dGTP into the heteroduplex DNA/DNA 31/21-mer were determined under single turnover conditions (Figure 2), with the enzyme (RT $120 \mathrm{nM})$ in slight excess of the template-primer $(31 \mathrm{~T} / 21 \mathrm{P}, 100 \mathrm{nM})$. Elongation product formation was quantified and plotted versus time, and the data for each time course was fit to a single exponential to provide the rate of incorporation (Figure 2 (a), center and right panels). Kinetic parameters, $k_{\text {pol }}$ and $K_{\mathrm{d}}$ were obtained after plotting the first-order rates versus nucleotide concentration, and fitting the data to a hyperbola (Figure 2 (b),(c)). Misinsertion ratios were in the range of $1.7 \times 10^{-5}$ to $9.7 \times 10^{-5}$ for all misincorporations tested, but differences among the mutant and wild-type RTs were relatively small. The only significant difference with the wild-type RT was observed with mutant V75I that showed a 2.6-fold reduced misinsertion ratio for the incorporation of $\mathrm{C}$ instead of $\mathrm{T}$. As previously described by other authors, ${ }^{37,38}$ large reductions in the catalytic efficiencies of misincorporation of $\mathrm{C}$ or $\mathrm{G}$ opposite A were a consequence of the loss of affinity for the nucleotide binding site and the lower incorporation rates $\left(k_{\mathrm{pol}}\right)$, in comparison with those obtained for the incorporation of the correct nucleotide. However, it should be noted that the low $k_{\mathrm{pol}}$ values of nucleotide misincorporation may not reflect a true catalytic constant, since the rate of dissociation of the $\mathrm{RT} \bullet \mathrm{DNA} \bullet \mathrm{dNTP}$ complex is expected to be high. ${ }^{37,39}$ Although $k_{\mathrm{off}} \mathrm{s}$ for the ternary complex were not determined, the results of nucleotide incorporation assays carried out with wild-type and mutant RTs in the presence of a DNA trap, suggested that the obtained $k_{\mathrm{pol}} \mathrm{S}$ for nucleotide 
misincorporation were largely influenced by the disruption of the RT $\bullet$ DNA $\bullet$ dNTP complex (data not shown).

\section{Pre-steady-state kinetic analysis of nucleotide incorporation on mismatched template- primers}

The kinetic parameters obtained in the misinsertion experiments described above suggested that the misinsertion step does not make a significant contribution to the fidelity differences between wild-type and mutant RTs. Therefore, we examined the pre-steady-state kinetics of mismatch extension, a step required for fixation of the mutation. In these experiments we analyzed the incorporation of dTTP (a correct nucleotide) onto three different mismatched 3' ends (G:T, G:G and G:A), using template-primers 31T/21PT, 31T/21PG and 31T/21PA, respectively. Reaction rate constants $\left(k_{\text {obs }}\right)$ were determined under single turnover conditions and using an excess of enzyme (120 nM) over substrate (31/21-mer, $100 \mathrm{nM})$, and then measuring the products formed at different dTTP concentrations (Figure 3 (a)). The plots of the first-order rate constants $\left(k_{\mathrm{obs}}\right)$ for nucleotide incorporation versus the dTTP concentrations, obtained wild-type and mutant RTs using different mismatched-template primers are given in Figures 3 (b) and 3 (c), respectively. Table 5 summarizes the kinetic parameters for nucleotide incorporation on mismatched template-primers, for all tested RTs. As expected, all RTs showed higher mismatched extension ratios for G:T mispairs than for G:G or G:A mispairs.

Extension of G:T mispairs by wild-type RT proceeds at a slower rate due to a 5-fold reduction in the $k_{\text {pol }}$, while the $K_{\mathrm{d}}$ increases by approximately 200 -fold. These data suggest that dNTP binding is responsible for the lower efficiency of G:T mispair extension. As observed in the case of nucleotide misincorporation, the lower $k_{\mathrm{pol}}$ values could reflect the off-rates for the ternary complex RT $\bullet$ DNA $\bullet$ dNTP. Although the dissociation of the ternary complex could explain in part the lower rates of dTTP incorporation on G:T mispairs, $k_{\mathrm{pol}}$ values were even 
lower on G:G and G:A mispairs. These data would be consistent with the formation of a "deadend" complex in the presence of G:G and G:A mispairs. ${ }^{39,40}$ In this scenario, the kinetics of mispair extension could reflect the sliding rate of the mismatch between the the pre- and posttranslocated states.

Our results indicate that mispair extension efficiencies of the wild-type RT and the mutant V75A were very similar. In contrast, V75F and V75I showed reduced mispair extension efficiencies. In the case of V75I, there was a 3.2-fold reduction of the G:T mismatch extension ratio, which resulted from the larger increase in the apparent $K_{\mathrm{d}}$ value (Table 5). While differences in mispair extension efficiencies between wild-type RT and mutant V75A were relative small, V75I showed increased fidelity with all three mispairs tested in this assay. For V75F, differences were relatively small, except for G:G mispair extensions, which were elongated at a very low rate by this mutant.

\section{M13mp2 lacZa forward and reversion mutation assays}

The influence of amino acid substitutions affecting Val-75 of HIV-1 RT on its mutation rate was assessed using and M13-based forward mutation assay with lacZ $\alpha$ as a reporter gene. ${ }^{41}$ Mutations generated when the RT copies the gapped region of the lacZ gene in M13mp2 can be scored by the number of plaques with altered colour phenotype (pale blue or colorless) in a specific indicator strain. The mutant frequency is then calculated as the ratio of mutant to total plaques. The results shown in Table 6 revealed that the wild-type HIV-1 RT was slightly more faithful than the RT having mutation V75A. In contrast, mutant frequencies obtained with mutants V75F and V75I were 1.8 and 3.0 times smaller than those obtained with the wild-type RT. The higher fidelity conferred by the substitution of Ile for Val-75 was further confirmed using an M13mp2 lacZ $\alpha$ reversion mutation assay. In this assay, the template strand of the lac Z gene contains an amber (TGA) codon that inactivates the nonessential $\alpha$-complementation 
activity. ${ }^{42}$ Polymerase errors introduced at this codon may restore the $\alpha$-complementation activity, rendering blue plaques. The mutant frequency obtained with the wild-type HIV-1 RT was around 3.5 times higher than the mutant frequency determined for the mutant V75I RT (Table 6), a result broadly in agreement with the data collected from misinsertion and mispair extension fidelity assays.

\section{Discussion}

The $\beta 3-\beta 4$ hairpin loop (residues 56-77) of the fingers subdomain in the $66-\mathrm{kDa}$ subunit of the HIV-1 RT undergoes a large conformational change upon dNTP binding. ${ }^{3,43}$ Residues in the $\beta 3$ - $\beta 4$ hairpin loop, which are often involved in nucleoside analogue resistance, ${ }^{44-46}$ directly contact the incoming dNTP as well as indirectly influence its binding via interactions with the template base. The comparison of the crystal structures of HIV-1 RT binary and ternary complexes revealed that the $5^{\prime}$ single-stranded template gets closer to the peptide backbone of Val-75 in the ternary complex (Figure 4). Several carbon atoms within the ribose moiety of the template nucleotide at position +1 are located less than $4 \AA$ away from the $-\mathrm{CO}$ - group of Val$75,{ }^{3}$ with the $\mathrm{C} 1$ ' atom at a distance of $3.44 \AA$ (Figure 4 (b)). In contrast, in binary complexes of HIV-1 RT and double stranded DNA, there is a larger distance between the ribose moiety of template nucleotide +1 and the peptide backbone of Val-75. Thus, in complexes containing a DNA duplex with an overhang of only one nucleotide (e.g. Protein Data Bank file 2HMI), the peptide backbone of Val-75 is at $4.29 \AA$ of the $\mathrm{C}^{\prime}$ ' atom of the ribose, while on average the ribose ring atoms are more than $5.5 \AA$ away from Val- $75^{47}$ (Figure 4 (d)). A similar topology was observed in the binary complex containing an RNA/DNA hybrid with a one-nucleotide overhang. ${ }^{48}$ Interestingly, in an HIV-1 RT/dsDNA binary complex containing a 5 ' template overhang of 3 nucleotides, the interaction between the $-\mathrm{NH}-$ and $-\mathrm{CO}-$ groups of the peptide backbones of Val-75 and Gln-151 was maintained, but the - $\mathrm{CO}$ - group of Val-75 was found to 
be closer to the nitrogen base of the template nucleotide +1 than to its ribose moiety ${ }^{49}$ (Figure 4 (c)). Taken together, these observations suggested that Val-75 plays a role in positioning the template nucleotide +1 , once the ternary complex is formed. In addition, the side-chain of Val75 interacts with residues such as Val-60, Phe-77 or Tyr-146, that are important to maintain the structure of the fingers subdomain while influencing the architecture of the dNTP binding site. ${ }^{35}$

The mutational analysis of Val-75 of HIV-1 RT has revealed that this position is rather tolerant to change, although some mutations appear to have an influence on nucleotide specificity and fidelity of DNA synthesis. Thus, substituting Ile or Phe for Val-75 increased the accuracy of the polymerase, while the substitution of Ala for Val-75 led to a modest but significant reduction of the enzyme's fidelity. Interestingly, those effects were consistently detected with the different types of assays used: (i) primer extensions in the absence of one dNTP, (ii) nucleotide misincorporation and mispair extension under steady-state conditions, (iii) nucleotide misincorporation and mispair extension under pre-steady-state conditions, and (iv) M13 lacZ-based forward mutation assays. The largest effects were observed with mutant V75I that showed a 3-fold increased accuracy in forward mutation assays. A similar increase (3.5fold) was also obtained with this mutant in a reversion mutation assay.

Mechanistic insights into the role of Val-75 in fidelity of DNA synthesis were obtained from kinetic assays. The events leading to the fixation of a mutation involve nucleotide misincorporation, followed by extension of a mispaired template-primer. ${ }^{6-8}$ Kinetic parameters obtained under steady-state conditions showed that the increased fidelity of V75I and V75F was a consequence of their lower mispair extension efficiencies in comparison with the wild-type RT. However, a mechanistic interpretation of the data based on the steady-state kinetic parameters $k_{\text {cat }}$ and $K_{\mathrm{m}}$ is problematical due to the fact that $K_{\mathrm{m}}$ differences in dNTP binding are largely governed by $k_{\mathrm{pol}}$. Therefore, we performed pre-steady-state kinetic analysis on Val-75 mutants in order to identify which step was affected in the process leading to the generation of a 
mutation. As shown in Figure 5, in comparison with the wild-type RT, mutations conferring higher accuracy (i.e. V75I and V75F) showed significantly lower mispair extension ratios under both steady- and pre-steady-state conditions, without having a large impact on misincorporation.

Interestingly, the mutant V75I showed G:T, G:G and G:A mispair extension ratios which were around 3 to 5 times lower than those obtained with the wild-type RT under pre-steady-state conditions. In comparison with the wild-type enzyme, there was a larger increase in the $K_{\mathrm{d}}$ for the correct dNTP, in polymerization reactions carried out with mismatched template-primers and mutant V75I (Table 5). However, both wild-type HIV-1 RT and the mutant V75I showed similar catalytic efficiencies for the incorporation of dTTP on matched (G:C) template-primers (Table 4$)$, and similar catalytic constants $\left(k_{\mathrm{pol}}\right)$ for the incorporation of correct dNTPs on mismatched 3' ends (Table 5). Mutant V75F also showed decreased fidelity, although in this case, significant differences were observed only with G:G mispairs (Figure 5). As in the case of V75I, the $K_{\mathrm{d}}$ for the correct nucleotide increased around 5 times, although V75F caused a reduction in the $k_{\mathrm{pol}}$ for dTTP on G:G mismatched template-primers, which was not significant for the mutant having Ile instead of Val-75 (Table 5).

Although steady-state kinetic analysis has been widely used for analyzing fidelity of HIV-1 RT mutants, there are very few pre-steady-state kinetic studies dealing with the effects of mutations on fidelity of DNA synthesis. Thus, Feng and Anderson ${ }^{38}$ analyzed the effects of the lamivudine-resistance mutation $\mathrm{M} 184 \mathrm{~V}$ in misinsertion fidelity assays. Authors showed that this mutation had a relatively small effect on the RT's ability to discriminate between correct and incorrect nucleotides. Similar studies carried out with the single-amino acid variants V148I and Q151N revealed only small differences in nucleotide selectivity between both mutants and the wild-type RT, although V148I and Q151N showed reduced mispair extension efficiency in comparison with the wild-type RT. ${ }^{50}$ In the case of Q151N, this effect was largely attributed to its higher $K_{\mathrm{d}}$ for a correct nucleotide when a mismatched template-primer is used as substrate. 
These effects are similar to those reported here for V75I. However, the catalytic efficiency of Q151N is largely reduced in comparison with the wild-type enzyme, ${ }^{17,50}$ suggesting that this mutation is unlikely to appear in vivo, due to its detrimental effect on dNTP binding. In contrast, V75I and other mutants at this position retain significant DNA polymerase activity in incorporation assays carried out under different conditions (Tables 1 and 4 and in Figure 1).

These results were also consistent with the variability observed at Val-75 in vivo. Mutant virus carrying the drug-resistance-related mutations V75I and V75T were shown to replicate efficiently in various cell types. ${ }^{35,51}$ V75I emerges as a secondary mutation in HIV variants resistant to multiple dideoxynucleosides, ${ }^{31,32}$ and appeared as a compensatory mutation in virus carrying G190E, a substitution conferring resistance to several nonnucleoside RT inhibitors. ${ }^{34,52}$ In the case of multidrug-resistance, V75I appears together with Q151M and probably affects dNTP binding by altering the interaction of Gln-151 with the nitrogen base of the incoming dNTP, as well as other interactions within the core of the fingers subdomain (e.g. with the side chain of Phe-77). On the other hand, its compensatory effect in virus carrying mutation G190E could be related to the positioning of the template-primer. Although the peptide backbone of Val-75 interacts with the $5^{\prime}$ template overhang in the ternary complex of HIV-1 RT, we cannot rule out an indirect effect on Gln-151 and other residues in the dNTP binding site that could account for the observed differences in the fidelity of DNA synthesis.

\section{Materials and Methods}

\section{Reagents}

Stock solutions $(100 \mathrm{mM})$ of dNTPs and $\left[\gamma_{-}{ }^{32} \mathrm{P}\right] \mathrm{ATP}$ were obtained from GE Healthcare. DNA oligonucleotides 21P (5'-ATACTTTAACCATATGTATCC-3'), PG5-25 (5' CCAGAATGCTGGTAGGGCTATACAT-3'), 31T (5'-

TTTTTTTTTAGGATACATATGGTTAAAGTAT-3'), and D2-47 (5'- 
GGGATTAAATAAAATAGTAAGAATGTATAGCCCTACCAGCATTCTGG-3') were obtained from Life Technologies. Oligonucleotides 21P and PG5-25 were labelled at their 5' termini with $\left[\gamma_{-}{ }^{32} \mathrm{P}\right] \mathrm{ATP}$ and T4 polynucleotide kinase, and then annealed to their corresponding templates (31T and D2-47, respectively). Template-primer 31T/21P was used in rapid quench experiments, while D2-47/PG5-25 was used in steady state kinetic assays. All others reagents were purchased from Merck or Sigma.

\section{Phage and bacterial strains}

The bacteriophage M13mp2 was used to prepare the gapped duplex DNA substrate. M13 phage was grown in the E. coli strain NR9099 [ $\Delta$ (pro-lac), thi, ara, recA56/F' (proAB, $\left.\left.\operatorname{lac}_{\mathrm{q}} \mathrm{Z} \Delta \mathrm{M} 15\right)\right]$ to obtain the single-stranded and replicative DNA of M13. Electrocompetent $E$. coli strain $\mathrm{MC1} 1061$ [hsdR, $h s d \mathrm{M}+$, araD, $\Delta($ ara, leu $), \Delta($ lacIPOZY), galU, galK, strA] was used to generate the mutant phage. The $\alpha$-complementation strain of E. coli, CSH50 [ $\Delta$ (pro-lac), thi, $\left.\operatorname{ara}, \operatorname{str} \mathrm{A} / \mathrm{F}^{\prime}\left(\operatorname{pro} \mathrm{AB}, \operatorname{lac}_{\mathrm{q}} \mathrm{Z} \Delta \mathrm{M} 15, \operatorname{tra\mathrm {D}36}\right)\right]$, was used to visualize the phenotype of the mutant phage.

\section{Mutagenesis, expression and purification of recombinant RTs}

Site-directed mutagenesis was carried out with the Quik-Change Site-Directed Mutagenesis kit (Stratagene) using plasmids pRT6 ${ }^{53}$ or p66RTB ${ }^{54}$ as templates, and the

mutagenic primers: 5'-CAGTACTAAATGGAGAAAATTAGCAGATTTCAGAGAAC-3' and 5'-GTTCTCTGAAATCTGCTAATTTTCTCCATTTAGTACTG-3' for V75A, 5' CAGTACTAAATGGAGAAAATTATTCGATTTCAGAGAAC-3' and 5'GTTCTCTGAAATCGAATAATTTTCTCCATTTAGTACTG-3' for V75F, 5' -

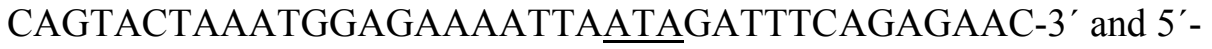
GTTCTCTGAAATCTATTAATTTTCTCCATTTAGTACTG-3' for V75I, 5'- 
CAGTACTAAATGGAGAAAATTACTAGATTTCAGAGAAC-3' and 5'-

GTTCTCTGAAATCTAGTAATTTTCTCCATTTAGTACTG-3' for V75L, 5' -

CAGTACTAAATGGAGAAAATTAATGGATTTCAGAGAAC-3' and 5'-

GTTCTCTGAAATCCATTAATTTTCTCCATTTAGTACTG-3' for V75M, 5'-

CAGTACTAAATGGAGAAAATTATCAGATTTCAGAGAAC-3' and 5'-

GTTCTCTGAAATCTGATAATTTTCTCCATTTAGTACTG-3' for V75S, 5'-

CAGTACTAAATGGAGAAAATTAACAGATTTCAGAGAAC-3' and 5'-

GTTCTCTGAAATCTGTTAATTTTCTCCATTTAGTACTG-3' for V75T (relevant codons

underlined), by following the manufacturer's instructions. After mutagenesis, the RT-coding regions were sequenced. Then, inserts containing the appropriate mutations were cloned in the p51 expression vector pT51H, by following previously described procedures. ${ }^{9,55}$

RTs were purified as described, after independent expression of their subunits (p66 and p51), ${ }^{44,56}$ using the constructs derived from pRT6 and pT51H. The $51 \mathrm{kDa}$ subunit was obtained with an extension of 14 amino acid residues at its $\mathrm{N}$-terminal end, which includes six consecutive histidine residues to facilitate its purification by metal chelate affinity chromatography. For those experiments requiring high concentrations of HIV-1 RT (i.e. determination of pre-steady-state kinetic parameters), RT expression and purification was performed with modified versions of plasmid p66RTB, ${ }^{57}$ as previously described. ${ }^{54}$ RT p66 subunits carrying a $\mathrm{His}_{6}$ tag at their C-terminus were co-expressed with $\mathrm{HIV}-1$ protease in $E$. coli XL1 Blue to obtain p66/p51 heterodimers, which were later purified by ionic exchange followed by affinity chromatography. ${ }^{54,57}$ Enzymes were quantified by active site titration ${ }^{37}$ before biochemical studies. 


\section{Extension of primers in the absence of one dNTP}

The template/primer D2-47/PG5-25 was used to determine the extent of misincorporation in the absence of one dNTP. Prior to the elongation reaction, PG5-25 was labelled at its $5^{\prime}$ terminus with $\left[\gamma^{32} \mathrm{P}\right] \mathrm{ATP}$ and T4 polynucleotide kinase, and annealed to the template (D2-47) in a solution containing $150 \mathrm{mM} \mathrm{NaCl}$ and $150 \mathrm{mM}$ magnesium acetate. ${ }^{11}$ Then, the template-primer was diluted 10-fold in $500 \mathrm{mM}$ Hepes ( $\mathrm{pH} 7.0$ ), containing $150 \mathrm{mM}$ $\mathrm{NaCl}$ and $150 \mathrm{mM}$ magnesium acetate. Assays were carried out for 0 to $60 \mathrm{~min}$ at $37^{\circ} \mathrm{C}$ with 24 $\mathrm{nM}$ RT, in $10 \mu \mathrm{l}$ of $50 \mathrm{mM}$ Hepes ( $\mathrm{pH} 7.0$ ), $15 \mathrm{mM} \mathrm{NaCl}, 15 \mathrm{mM}$ magnesium acetate, $130 \mathrm{mM}$ $\mathrm{KCH}_{3} \mathrm{COO}, 1 \mathrm{mM}$ DTT, $5 \%(\mathrm{w} / \mathrm{v})$ polyethylene glycol, and dNTPs at a concentration of 500 $\mu \mathrm{M}$ each (*: dATP, dCTP, dTTP; -A: dCTP, dTTP; -T: dATP, dCTP; and -C: dATP, dTTP). The template-primer concentration in the assay was $22.5 \mathrm{nM}$. At the end of the incubation period, the reactions were stopped by adding $4 \mu \mathrm{l}$ of stop solution (10 mM EDTA in $90 \%$ formamide containing $3 \mathrm{mg} / \mathrm{ml}$ xylene cyanol $\mathrm{FF}$ and $3 \mathrm{mg} / \mathrm{ml}$ bromophenol blue) and incubated at $90^{\circ} \mathrm{C}$ for $10 \mathrm{~min}$. Reaction products were separated in denaturing $20 \%$ polyacrylamide $/ 8 \mathrm{M}$ urea gels, and visualized by phosphorimaging with a BAS 1500 scanner (Fuji).

\section{Steady-state kinetic assays}

Fidelity assays were performed as previously described. ${ }^{58-60}$ Assays were carried out in 10-12 $\mu 1$ of $50 \mathrm{mM}$ Hepes ( $\mathrm{pH} 7.0$ ), $15 \mathrm{mM} \mathrm{NaCl}, 15 \mathrm{mM}$ magnesium acetate, $130 \mathrm{mM}$ $\mathrm{KCH}_{3} \mathrm{COO}, 1 \mathrm{mM}$ DTT and 5\% (w/v) polyethylene glycol 6000. The template-primer used in misinsertion fidelity assays was D2-47/PG5-25. For mispair extension fidelity assays, three additional primers were used instead of PG5-25 (i.e. PG5-25C, PG5-25G and PG5-25A). All of them were identical to PG5-25, but they had C, G, or A (instead of T), at their 3' end. Template-primer concentrations were $30 \mathrm{nM}$ in all assays. Nucleotide concentrations in the range of $10 \mathrm{nM}-1 \mathrm{mM}$ were used to measure dTTP incorporation, while incorrect dNTP 
concentrations ranged from 0.1 to $10 \mathrm{mM}$ in the assays. For the extension of mismatched template-primers, dTTP concentrations used were in the range of $10 \mu \mathrm{M}-5 \mathrm{mM}$. The active enzyme concentration was around 6-10 $\mathrm{nM}$. The rate of product formation was measured for 1012 different concentrations of each correct or incorrect dNTP. After incubation at $37^{\circ} \mathrm{C}$, products were heat-denatured, resolved in $20 \%$ polyacrylamide/ $8 \mathrm{M}$ urea gels and quantified with a BAS 1500 scanner (Fuji) using the program Tina version 2.09 (Raytest Isotopenmessegerate Gmbh Staubenhardt, Germany). The catalytic constants $k_{\text {cat }}$ and $K_{\mathrm{m}}$ were determined after fitting the elongation data to the Michaelis-Menten equation.

\section{Pre-steady-state kinetic assays}

Pre-steady-state kinetic parameters for the incorporation of dTTP by wild-type and mutant HIV-1 RTs were determined with a rapid quench instrument (model QFM-400, BioLogic Science Instruments, Claix, France) with reaction times ranging from $10 \mathrm{~ms}$ to $6 \mathrm{~s} .^{37}$ Reactions were performed by mixing $12 \mu \mathrm{l}$ of a solution containing $50 \mathrm{nM}$ (active sites) of HIV$1 \mathrm{RT}$ and $100 \mathrm{nM}$ of the template/primer 31T/21P in RT buffer [50 mM Tris- $\mathrm{HCl}(\mathrm{pH} \mathrm{8.0),} 50$ $\mathrm{mM} \mathrm{KCl}, 0.05 \%(\mathrm{v} / \mathrm{v})$ Triton X-100] with $12 \mu \mathrm{l}$ of RT buffer containing different concentrations of dNTP in the presence of $12-18 \mathrm{mM} \mathrm{MgCl}_{2}$. At appropriate times, reactions were quenched with EDTA (0.3 M final concentration). For studying misinsertion and mismatched primer extension fidelity, reactions involving the incorporation of incorrect nucleotides and the mispair extension (i.e. the incorporation of dCTP and dGTP on 31T/21P or the extension of G:T, G:G and G:A mispairs) were conducted with excess concentrations of enzyme (120 nM) over the template-primer duplex $(100 \mathrm{nM})$. These conditions were chosen to eliminate the influence of the enzyme turnover rate $\left(k_{\mathrm{ss}}\right)$, which interferes in the measurements of low incorporation rates.

For mispair extension fidelity assays, ${ }^{61}$ three additional primers were used: $21 \mathrm{PT}, 21 \mathrm{PG}$ and 21PA. All of them were identical to 21P, but had T, G, or A (instead of C), at their 3' 
terminus. Misincorporation and mispair extension reactions were performed in the buffer conditions described above, using a rapid quench instrument. When the reaction times were longer than $8 \mathrm{~s}$, the assays were carried out manually. The reaction products were separated on a $20 \%(\mathrm{w} / \mathrm{v})$ polyacrylamide/8 $\mathrm{M}$ urea gel, and quantified by phosphorimaging with a BAS 1500 scanner (Fuji). The formation of product $[\mathrm{P}]$ over time was fitted with the burst equation:

$[\mathrm{P}]=\mathrm{A} \times\left[1-\exp \left(-k_{\text {obs }} \times \mathrm{t}\right)\right]+k_{\mathrm{ss}} \times \mathrm{t}$

where $\mathrm{A}$ is the amplitude of the burst, $k_{\mathrm{obs}}$ is the apparent kinetic constant of formation of the phosphodiester bond, and $k_{\mathrm{ss}}$ is the enzyme turnover rate, i.e. the kinetic constant of the steadystate linear phase. Data from single-turnover experiments were fitted to a single-exponential equation that measures the rate of dNTP incorporation $\left(k_{\mathrm{obs}}\right)$ per given $\mathrm{dNTP}$ concentration ([dNTP]). The dependence of $k_{\mathrm{obs}}$ on [dNTP] is described by the hyperbolic equation:

$k_{\mathrm{obs}}=k_{\mathrm{pol}} \mathrm{x}[\mathrm{dNTP}] /\left(K_{\mathrm{d}}+[\mathrm{dNTP}]\right)$

where $K_{\mathrm{d}}$ and $k_{\mathrm{pol}}$ are the equilibrium constant and the catalytic rate constant of the dNTP for RT, respectively. $K_{\mathrm{d}}$ and $k_{\mathrm{pol}}$ were determined from curve-fitting using Sigma Plot.

\section{M13mp2 lacZa forward and reversion mutation assays}

Mutation frequencies for wild-type and mutant HIV-1 RTs were determined as described

previously. ${ }^{41}$ M13mp2 DNA containing a single-stranded gap of 361 nucleotides was prepared as described $^{41}$ and used as a template/primer for fill-in DNA synthesis reactions by wild-type and mutant RTs. In the forward mutation assay, polymerase errors that inactivate the nonessential $\alpha$-complementation activity of the lacZ gene in bacteriophage M13mp2 are scored as light blue or colourless plaques. In this assay, mutant phenotypes can be the result of nucleotide changes at 125 different sites in the lacZ gene. In the reversion mutation assay the starting DNA substrate contains an inactivating base-substitution in the lac Z gene. Polymerase 
errors that restore partial or full $\alpha$-complementation activity to yield a blue plaque phenotype are scored. Fill-in reactions were carried out with gapped M13mp2 DNA (50 ng), purified RT (100 $\mathrm{nM})$, and the four dNTPs ( $250 \mu \mathrm{M}$ each) in $10 \mu \mathrm{l}$ of $25 \mathrm{mM}$ Tris- $\mathrm{HCl}(\mathrm{pH} 8.0)$ buffer, containing $100 \mathrm{mM} \mathrm{KCl}, 2 \mathrm{mM}$ DTT and $4 \mathrm{mM} \mathrm{MgCl}_{2}$. Reactions were incubated for $30 \mathrm{~min}$ at $37^{\circ} \mathrm{C}$, and then stopped by adding $1 \mu 1$ of $60 \mathrm{mM}$ EDTA. Complete synthesis across the gapped region was confirmed by agarose gel electrophoresis. ${ }^{41}$ Two independent gap filling reactions were performed for RT proteins. Reaction products were introduced into E. coli strain MC1061 by electroporation. Transformed cells were plated to M9 plates containing 5-bromo-4-chloro-3indolyl- $\beta$-D-galactopyranoside (X-gal) and isopropyl-1-thio- $\beta$-D-galactopyranoside (IPTG) with CSH50 lawn cells. The mutation frequency was determined as the ratio of mutant plaques (light blue and colourless in the forward mutation assay, or blue in the reversion assay) to mutant plus wild type plaques (dark blue in the forward mutation assay or colourless in the reversion assay), as described. ${ }^{41}$ The background mutation frequency was determined by electroporating unfilled gapped duplex and scoring for mutant plaques as described above.

\section{Acknowledgements}

We thank Magda Galović for excellent technical assistance. Work in Madrid was supported in part by grants of the Spanish Ministry of Education and Science (BIO2003/01175), Fondo de Investigación Sanitaria (through "Red Temática de Investigación Cooperativa en SIDA" RD06/0006), and an institutional grant of Fundación Ramón Areces. T. M. is a recipient of a predoctoral fellowship of the Spanish Ministry of Education and Science. 


\section{References}

1. Basavapathruni, A. \& Anderson, K. S. (2007) Reverse transcription of the HIV-1 pandemic. FASEB J., doi:10.1096/fj.07-8697rev

2. Kohlstaedt, L. A., Wang, J., Friedman, J. M., Rice, P. A. \& Steitz, T. A. (1992). Crystal structure at $3.5 \AA$ resolution of HIV-1 reverse transcriptase complexed with an inhibitor. Science 256, 1783-1790.

3. Huang, H., Chopra, R., Verdine, G. L. \& Harrison, S. C. (1998). Structure of a covalently trapped catalytic complex of HIV-1 reverse transcriptase: Implications for drug resistance. Science 282, 1669-1675

4. Larder, B. A., Kemp, S. D. \& Purifoy, D. J. M. (1989). Infectious potential of human immunodeficiency virus type 1 reverse transcriptase mutants with altered inhibitor sensitivity. Proc. Natl. Acad. Sci. U.S.A. 86, 4803-4807.

5. Le Grice, S. F. J., Naas, T., Wohlgensinger, B. \& Schatz, O. (1991). Subunit-selective mutagenesis indicates minimal polymerase activity in heterodimer-associated p51 HIV-1 reverse transcriptase. EMBO J. 10, 3905-3911.

6. Kunkel, T. A. (2004). DNA replication fidelity. J. Biol. Chem. 279, 16895-16898.

7. Menéndez-Arias, L. (2002). Molecular basis of fidelity of DNA synthesis and nucleotide specificity of retroviral reverse transcriptases. Progr. Nucleic Acid Res. Mol. Biol. 71, 91147.

8. Rezende, L. F. \& Prasad, V. R. (2004). Nucleoside-analogue resistance mutations in HIV-1 RT and their influence on polymerase fidelity and viral mutation rates. Int. J. Biochem. Cell Biol. 36, 1716-1734. 
9. Martín-Hernández, A. M., Domingo, E. \& Menéndez-Arias, L. (1996). Human immunodeficiency virus type 1 reverse transcriptase: role of Tyr115 in deoxynucleotide binding and misinsertion fidelity of DNA synthesis. EMBO J. 15, 4434-4442.

10. Pandey, V. N., Kaushik, N., Rege, N., Sarafianos, S. G., Yadav, P. N. S. \& Modak, M. J. (1996). Role of methionine 184 of human immunodeficiency virus type-1 reverse transcriptase in the polymerase function and fidelity of DNA synthesis. Biochemistry 35, $2168-2179$.

11. Martín-Hernández, A. M., Gutiérrez-Rivas, M., Domingo, E. \& Menéndez-Arias, L. (1997). Mispair extension fidelity of human immunodeficiency virus type 1 reverse transcriptases with amino acid substitutions affecting Tyr115. Nucleic Acids Res. 25, 1383-1389.

12. Lewis, D. A., Bebenek, K.,Beard, W. A., Wilson, S. H. \& Kunkel, T. A. (1999). Uniquely altered DNA replication fidelity conferred by an amino acid change in the nucleotide binding pocket of human immunodeficiency virus type 1 reverse transcriptase. J. Biol. Chem. 274, 32924-32930.

13. Cases-González, C. E., Gutiérrez-Rivas, M. \& Menéndez-Arias, L. (2000). Coupling ribose selection to fidelity of DNA synthesis - The role of Tyr-115 of human immunodeficiency virus type 1 reverse transcriptase. J. Biol. Chem. 275, 19759-19767.

14. Wainberg, M. A., Drosopoulos, W. C., Salomon, H., Hsu, M., Borkow, G., Parniak, M. A., Gu, Z., Song, Q., Manne, J., Islam, S., Castriota, G. \& Prasad, V. R. (1996). Enhanced fidelity of 3TC-selected mutant HIV-1 reverse transcriptase. Science 271, 1282-1285.

15. Drosopoulos, W. C. \& Prasad V. R. (1998). Increased misincorporation fidelity observed for nucleoside analog resistance mutations M184V and E89G in human immunodeficiency virus type 1 reverse transcriptase does not correlate with the overall error rate measured in vitro. J. Virol. 72, 4224-4230. 
16. Harris, D., Kaushik, N., Pandey, P. K., Yadav, P. N. S. \& Pandey, V. N. (1998). Functional analysis of amino acid residues constituting the dNTP binding pocket of HIV-1 reverse transcriptase. J. Biol. Chem. 273, 33624-33634.

17. Weiss, K. K., Bambara, R. A. \& Kim, B. (2002). Mechanistic role of residue $\mathrm{Gln}^{151}$ in error prone DNA synthesis by human immunodeficiency virus type $1(\mathrm{HIV}-1)$ reverse transcriptase (RT) - Pre-steady state kinetic study of the Q151N HIV-1 RT mutant with increased fidelity. J. Biol. Chem. 277, 22662-22669.

18. Wisniewski, M., Palaniappan, C., Fu, Z., Le Grice, S. F. J., Fay, P. \& Bambara, R. A. (1999). Mutations in the primer grip region of HIV reverse transcriptase can increase replication fidelity. J. Biol. Chem. 274, 28175-28184.

19. Gutiérrez-Rivas, M. \& Menéndez-Arias, L. (2001). A mutation in the primer grip region of HIV-1 reverse transcriptase that confers reduced fidelity of DNA synthesis. Nucleic Acids Res. 29, 4963-4972.

20. Cases-González, C. E. \& Menéndez-Arias, L. (2004). Increased G $\rightarrow$ A transition frequencies displayed by primer grip mutants of human immunodeficiency virus type 1 reverse transcriptase. J. Virol. 78, 1012-1019.

21. Hamburg, M. E., Curr, K. A., Monaghan, M., Rao, V. R., Tripathi, S., Preston, B. D., Sarafianos, S., Arnold, E., Darden, T. \& Prasad, V. R. (2006). Structural determinants of slippage-mediated mutations by human immunodeficiency virus type 1 reverse transcriptase. J. Biol. Chem. 281, 7421-7428.

22. Beard, W. A., Stahl, S. J., Kim, H.-R., Bebenek, K., Kumar, A., Strub, M.-P., Becerra, S. P., Kunkel, T. A. \& Wilson, S. H. (1994). Structure/function studies of human immunodeficiency virus type 1 reverse transcriptase - Alanine scanning mutagenesis of an a-helix in the thumb subdomain. J. Biol. Chem. 269, 28091-28097. 
23. Mbisa, J. L., Nikolenko, G. N. \& Pathak, V. K. (2005). Mutations in the RNase H primer grip domain of murine leukemia virus reverse transcriptase decrease efficiency and accuracy of plus-strand DNA transfer. J. Virol. 79, 419-427.

24. Rubinek, T., Bakhanashvili, M., Taube, R., Avidan, O. \& Hizi, A. (1997). The fidelity of 3' misinsertion and mispair extension during RNA synthesis exhibited by two drug-resistant mutants of the reverse transcriptase of human immunodeficiency virus type 1 with Leu $74 \rightarrow$ Val and Glu89 $\rightarrow$ Gly. Eur. J. Biochem. 247, 238-247.

25. Kim, B., Hathaway, T. R. \& Loeb, L. A. (1998). Fidelity of mutant HIV-1 reverse transcriptases: Interaction with the single-stranded template influences the accuracy of DNA synthesis. Biochemistry 37, 5831-5839.

26. Kim, B., Ayran, J. C., Sagar, S. G., Adman, E. T., Fuller, S. M., Tran, N. H. \& Horrigan, J. (1999). New human immunodeficiency virus type 1 reverse transcriptase (HIV-1 RT) mutants with increased fidelity of DNA synthesis: Accuracy, template binding, and processivity. J. Biol. Chem. 274, 27666-27673.

27. Shah, F. S., Curr, K. A., Hamburgh, M. E., Parniak, M., Mitsuya, H., Arnez, J. G. \& Prasad, V. R. (2000). Differential influence of nucleoside analog-resistance mutations K65R and L74V on the overall mutation rate and error specificity of human immunodeficiency virus type 1 reverse transcriptase. J. Biol. Chem. 275, 27037-27044.

28. Fisher, T. S. \& Prasad, V. R. (2002). Substitutions of $\mathrm{Phe}^{61}$ located in the vicinity of template 5 '-overhang influence polymerase fidelity and nucleoside analog sensitivity of HIV-1 reverse transcriptase. J. Biol. Chem. 277, 22345-22352.

29. Menéndez-Arias, L. (2002). Targeting HIV: antiretroviral therapy and development of drug resistance. Trends Pharmacol. Sci. 23, 381-388. 
30. Clark, S. A., Calef, C. \& Mellors, J. W. (2005). Mutations in retroviral genes associated with drug resistance. In HIV Sequence Compendium 2005 (Leitner, T., Foley, B., Hahn, B., Marx, P., McCutchan, F., Mellors, J., Wolinsky, S. \& Korber, B., eds), pp. 80-174, Theoretical Biology and Biophysics Group, Los Alamos National Laboratory, Los Alamos, New Mexico, USA.

31. Shirasaka, T., Kavlick, M. F., Ueno, T., Gao, W.-Y., Kojima, E., Alcaide, M. L., Chokekijchai, S., Roy, B. M., Arnold, E., Yarchoan, R. \& Mitsuya, H. (1995). Emergence of human immunodeficiency virus type 1 variants with resistance to multiple dideoxynucleosides in patients receiving therapy with dideoxynucleosides. Proc. Natl. Acad. Sci. U.S.A. 92, 2398-2402.

32. Iversen, A. K. N., Shafer, R.W., Wehrly, K., Winters, M.A., Mullins, J.I., Chesebro, B. \& Merigan, T. C. (1996). Multidrug-resistant human immunodeficiency virus type 1 strains resulting from combination antiretroviral therapy. J. Virol. 70, 1086-1090.

33. Lacey, S. F. \& Larder, B. A. (1994). Novel mutation (V75T) in human immunodeficiency virus type 1 reverse transcriptase confers resistance to $2^{\prime}, 3^{\prime}$-didehydro- $2^{\prime}, 3^{\prime}-$ dideoxythymidine in cell culture. Antimicrob. Agents Chemother. 38, 1428-1432.

34. Kleim, J.-P., Rösner, M., Winkler, I., Paessens, A., Kirsch, R., Hsiou, Y., Arnold, E. \& Riess, G. (1996). Selective pressure of a quinoxaline nonnucleoside inhibitor of human immunodeficiency virus type 1 (HIV-1) reverse transcriptase (RT) on HIV-1 replication results in the emergence of nucleoside RT-inhibitor-specific (RT Leu-74 $\rightarrow$ Val or Ile and Val-75 $\rightarrow$ Leu or Ile) HIV-1 mutants. Proc. Natl. Acad. Sci. U.S.A. 93, 34-38.

35. Selmi, B., Boretto, J., Navarro, J.-M., Sire, J., Longhi, S., Guerreiro, C., Mulard, L., Sarfati, S. \& Canard, B. (2001). The valine-to-threonine 75 substitution in human immunodeficiency vírus type 1 reverse transcriptase and its relation with stavudine resistance. J. Biol. Chem. 276, 13965-13974. 
36. Wilson, J. E., Aulabaugh, A., Caligan, B., McPherson, S., Wakefield, J. K., Jablonski, S., Morrow, C. D., Reardon, J. E. \& Furman, P. A. (1996). Human immunodeficiency virus type-1 reverse transcriptase: Contribution of Met-184 to binding of nucleoside 5'triphosphate. J. Biol. Chem. 271, 13656-13662.

37. Kati, W. M., Johnson, K. A., Jerva, L. F. \& Anderson, K. S. (1992). Mechanism and fidelity of HIV reverse transcriptase. J. Biol. Chem. 267, 25988-25997.

38. Feng, J. Y. \& Anderson, K. S. (1999). Mechanistic studies examining the efficiency and fidelity of DNA synthesis by the 3TC-resistant mutant (184V) of HIV-1 reverse transcriptase. Biochemistry 38, 9440-9448.

39. Wöhrl, B., Krebs, R., Goody, R. S. \& Restle, T. (1999). Refined model for primer/template binding by HIV-1 reverse transcriptase: Pre-steady-state kinetic analyses of primer/template binding and nucleotide incorporation events distinguish between different binding modes depending on the nature of the nucleic acid substrate. J. Mol. Biol. 292, 333-344.

40. Marchand, B. \& Götte, M. (2004). Impact of the translocational equilibrium of HIV-1 reverse transcriptase on the efficiency of mismatch extensions and the excision of mispaired nucleotides. Int. J. Biochem. Cell Biol. 36, 1823-1835.

41. Bebenek, K. \& Kunkel, T. A. (1995). Analyzing fidelity of DNA polymerases. Methods Enzymol. 262, 217-232.

42. Eckert, K. A. \& Kunkel, T. A. (1993). Fidelity of DNA synthesis catalyzed by human DNA polymerase $\alpha$ and HIV-1 reverse transcriptase: Effect of reaction $\mathrm{pH}$. Nucleic Acids Res. 21, 5212-5220.

43. Mendieta, J., Cases-González, C. E., Matamoros, T., Ramírez, G. \& Menéndez-Arias, L. (2007). $\mathrm{A} \mathrm{Mg}^{2+}$-induced conformational switch rendering a competent DNA polymerase catalytic complex. Proteins, doi:10.1002/prot.21711 
44. Matamoros, T., Franco, S., Vázquez-Álvarez, B. M., Mas, A., Martínez, M. A. \& Menéndez-Arias, L. (2004). Molecular determinants of multi-nucleoside analogue resistance in HIV-1 reverse transcriptases containing a dipeptide insertion in the fingers subdomain: Effect of mutations D67N and T215Y on removal of thymidine nucleotide analogues from blocked DNA primers. J. Biol. Chem. 279, 24569-24577.

45. Cases-González, C. E., Franco, S., Martínez, M. A. \& Menéndez-Arias, L. (2007). Mutational patterns associated with the 69 insertion complex in multi-drug-resistant HIV-1 reverse transcriptase that confer increased excision activity and high-level resistance to zidovudine. J. Mol. Biol. 365, 298-309.

46. Menéndez-Arias, L., Matamoros, T. \& Cases-González, C. E. (2006). Insertions and deletions in HIV-1 reverse transcriptase: Consequences for drug resistance and viral fitness. Curr. Pharm. Des. 12, 1811-1825.

47. Ding, J., Das, K., Hsiou, Y., Sarafianos, S. G., Clark, A. D., Jr., Jacobo-Molina, A., Tantillo, C., Hughes, S. H. \& Arnold, E. (1998). Structural and functional implications of the polymerase active site region in a complex of HIV-1 RT with a double-stranded DNA template-primer and an antibody Fab fragment at $2.8 \AA$ resolution. J. Mol. Biol. 284, 10951111.

48. Sarafianos, S. G., Das, K., Tantillo, C., Clark, A. D., Jr, Ding, J., Whitcomb, J. M., Boyer, P. L., Hughes, S. H. \& Arnold, E. (2001). Crystal structure of HIV-1 reverse transcriptase in complex with a polypurine tract RNA:DNA. EMBO J. 20, 1449-1461.

49. Peletskaya, E. N., Kogon, A. A., Tuske, S., Arnold, E. \& Hughes, S. H. (2004). Nonnucleoside inhibitor binding affects the interactions of the fingers subdomain of human immunodeficiency virus type 1 reverse transcriptase with DNA. J. Virol. 78, 3387-3397. 
50. Weiss, K. K., Chen, R., Skasko, M., Reynolds, H. M., Lee, K., Bambara, R. A., Mansky, L. M. \& Kim, B. (2004). A role for dNTP binding of human immunodeficiency virus type 1 reverse transcriptase in viral mutagenesis. Biochemistry 43, 4490-4500.

51. Maeda, Y., Venzon, D. J. \& Mitsuya, H. (1999). Altered drug sensitivity, fitness, and evolution of human immunodeficiency virus type 1 with pol gene mutations conferring multi-dideoxynucleoside resistance. J. Infect. Dis. 177, 1207-1213.

52. Boyer, P. L., Gao, H.-Q. \& Hughes, S. H. (1998). A mutation at position 190 of human immunodeficiency virus type 1 reverse transcriptase interacts with mutations at positions 74 and 75 via the template primer. Antimicrob. Agents Chemother. 42, 447-452.

53. Quiñones-Mateu, M. E., Soriano, V., Domingo, E. \& Menéndez-Arias, L. (1997). Characterization of the reverse transcriptase of a human immunodeficiency virus type 1 group O isolate. Virology 236, 364-373.

54. Matamoros, T., Deval, J., Guerreiro, C., Mulard, L., Canard, B. \& Menendez-Arias, L. (2005). Suppression of multidrug-resistant HIV-1 reverse transcriptase primer unblocking activity by $\alpha$-phosphate-modified thymidine analogues. J. Mol. Biol. 349, 451-463.

55. Menéndez-Arias, L. (1998). Studies on the effects of truncating $\alpha$-helix E' of p66 human immunodeficiency virus type 1 reverse transcriptase on template-primer binding and fidelity of DNA synthesis. Biochemistry 37, 16636-16644.

56. Mas, A., Parera, M., Briones, C., Soriano, V., Martínez, M. A., Domingo, E. \& MenéndezArias, L. (2000). Role of a dipeptide insertion between codons 69 and 70 of HIV-1 reverse transcriptase in the mechanism of AZT resistance. EMBO J. 19, 5752-5761.

57. Boretto, J., Longhi, S., Navarro, J.-M., Selmi, B., Sire, J. \& Canard, B. (2001). An integrated system to study multiply substituted human immunodeficiency virus type 1 reverse transcriptase. Anal. Biochem. 292, 139-147. 
58. Boosalis, M. S., Petruska, J. \& Goodman, M. F. (1987). DNA polymerase insertion fidelity - Gel assay for site-specific kinetics. J. Biol. Chem. 262, 14689-14696.

59. Mendelman, L. V., Boosalis, M. S., Petruska, J. \& Goodman, M. F. (1989). Nearest neighbor influences on DNA polymerase insertion fidelity. J. Biol. Chem. 264, 1441514423.

60. Cases-González, C. E. \& Menéndez-Arias, L. (2005). Nucleotide specificity of HIV-1 reverse transcriptases with amino acid substitutions affecting Ala-114. Biochem. J. 387, $221-229$.

61. Zinnen, S., Hsieh, J. C. \& Modrich, P. (1994). Misincorporation and mispaired primer extension by human immunodeficiency virus reverse transcriptase. J. Biol. Chem. 269, $24195-24202$.

\section{FIGURE LEGENDS}

Figure 1. Primer extension by wild-type and mutant RTs in assays containing a DNA template (D2-47) and lacking a complementary dNTP. Reactions were incubated for 5, 15, 30 and 60 min, as shown. Lanes marked with an asterisk indicate that all three nucleotides are included in the dNTP mix. The lanes marked with $-\mathrm{A},-\mathrm{C}$ and $-\mathrm{T}$ represents the missing nucleotide from the dNTP mix in the respective set of experiments. P and F indicate the positions of the unextended primer and the fully-extended products, respectively. Prominent bands at positions +4 and +7 represent stop sites occurring after the incorporation of 4 and 7 nucleotides, respectively. Arrows are used to indicate bands representing specific stops produced by Val-75 mutants. Boxes are used to highlight the differences between the wild-type RT and mutants V75I and V75T. 
Figure 2. Nucleotide concentration dependence on the first-order rates for correct (dTTP), or incorrect (dCTP and dGTP) incorporation into DNA/DNA 31/21-mer. (a) Pre-steady-state kinetics of nucleotide incorporation by wild-type HIV-1 RT. Preincubated solutions of RT (50 $\mathrm{nM})$ and $\left[5\right.$ '- $\left.{ }^{32} \mathrm{P}\right]$ 31/21-mer $(100 \mathrm{nM})$ were mixed with increased concentrations of nucleotide in a buffer containing $12 \mathrm{mM} \mathrm{Mg}^{2+}$ to start the reactions. The reactions were quenched at the indicated times and analyzed in polyacrylamide gels. The solid lines represented the best fit of the data for dTTP incorporation to the burst equation (left panel). Center and right panels show the kinetics of dCTP and dGTP incorporation under single turnover conditions (i.e. excess of RT over template-primer). In both cases, data were fit to a single exponential equation. (b) The first-order rates measured above were plotted against the corresponding nucleotide concentration. The data were fit to a hyperbolic equation as described under "Materials and Methods". The solid lane represents the best fit of the data to the hyperbolic equation. (c) Concentration dependence of dTTP (left), dCTP (centre) or dGTP (right) incorporation into the

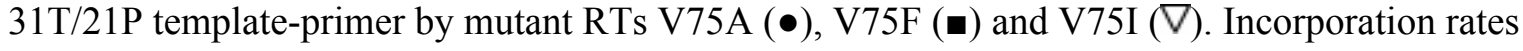
$\left(k_{\mathrm{obs}}\right)$, obtained from the corresponding burst or single exponential equations (not shown), were plotted against the nucleotide concentrations, and the data were fitted to the hyperbolic equation to obtain $K_{\mathrm{d}}$ and $k_{\mathrm{pol}}$ values. In all cases, kinetic parameters for correct nucleotide incorporations were determined in the presence of $12 \mathrm{mM} \mathrm{Mg}^{2+}$. Incorporation of dCTP and dGTP by mutants V75F and V75I was monitored in the presence of $18 \mathrm{mM} \mathrm{Mg}^{2+}$.

Figure 3. Nucleotide concentration dependence on the first-order rates for dTTP incorporation into DNA/DNA 31/21-mers with G:T, G:G or G:A mismatches at their 3' end. (a), Pre-steadystate kinetics of dTTP incorporation on a mismatched template-primer by wild-type HIV-1 RT. Preincubated solutions of RT (120 nM) and [5'- $\left.{ }^{32} \mathrm{P}\right]$ 31/21-mer (100 nM) were mixed with increased concentrations of nucleotide in a buffer containing $12 \mathrm{mM} \mathrm{Mg}^{2+}$ to start the reactions. 
The reactions were quenched at the indicated times and analyzed in polyacrylamide gels. The solid lines represented the best fit of the data to the single exponential equation. (b), The firstorder rates $\left(k_{\text {obs }}\right)$ measured above were plotted against the corresponding nucleotide concentration. The data were fit to a hyperbolic equation as described under "Materials and Methods". The solid lane represents the best fit of the data to the hyperbolic equation. (c), Concentration dependence of dTTP incorporation into the template-primers 31T/21PT (left), 31T/21PG (centre), and 31T/21PA (right) by mutant RTs V75A (•), V75F (匹) and V75I ( $\nabla)$. First-order rates, obtained from the corresponding equations (not shown), were plotted against the nucleotide concentrations, and the data were fitted to the hyperbolic equation to obtain $K_{\mathrm{d}}$ and $k_{\text {pol }}$ values. Mispair extensions catalyzed by mutant V75A were carried out in the presence of $\mathrm{Mg}^{2+}$ at a $12 \mathrm{mM}$ concentration, while reactions performed with $\mathrm{V} 75 \mathrm{~F}$ or $\mathrm{V} 75 \mathrm{I}$ were done in the presence of $18 \mathrm{mM} \mathrm{Mg}^{2+}$. Inhibition of the elongation reaction due to an excess of substrate was observed at dGTP concentrations above $12 \mathrm{mM}$ with all RTs. This effect was not neutralized by increasing the concentration of $\mathrm{Mg}^{2+}$.

Figure 4. Interactions between the peptide backbone of Val-75 of HIV-1 RT and neighbouring residues. (a) View of the DNA polymerase site showing the location of the dsDNA templateprimer (template strand in red and primer strand in white), and the incoming dNTP (yellow). Blue and green ribbon representations are used to indicate the location of the $66-\mathrm{kDa}$ and the $51-$ $\mathrm{kDa}$ subunits of the RT, respectively. The $\beta 3-\beta 4$ hairpin loop (shown in orange) contains Val75, which is represented with a CPK model. Location of Val-75 (yellow), Gln-151 (blue) and template nucleotide +1 (red) in the crystal structures of the ternary complex of HIV-1 RT $\bullet$ DNA/DNA $\bullet$ dTTP $\left(\right.$ PDB file 1RTD) ${ }^{3}$ (b), and binary complexes of HIV-1 RT and dsDNA (c and d). The structure shown in panel (c) corresponds to PDB file R0A, and contains a 5' template overhang of 3 nucleotides ${ }^{48}$ while in (d), the single-stranded template contains just one 
nucleotide (PDB file 2HMI). ${ }^{46}$ Representative intramolecular distances (in $\AA$ ) between peptide backbone groups in Val-75 and neighbouring residues are indicated. Reported distances between the - $\mathrm{CO}-$ group of Val-75 and the template nucleotide correspond to positions $\mathrm{N} 3$ (nitrogen base), $\mathrm{Cl}^{\prime}$ (ribose), and the average distance to the five atoms in the ribose ring.

Figure 5. Effect of RT mutations on the fidelity of DNA synthesis. Misincorporation efficiencies (a) and mispair extension efficiencies (b) for the wild-type HIV-1 RT and mutants V75A, V75F and V75I, as determined in steady-state kinetic assays (left) and in pre-steady-state kinetic assays (right).

\section{Abbreviations and footnotes}

Abbreviations used: HIV-1, human immunodeficiency virus type-1; RT, reverse transcriptase; dsDNA, double-stranded DNA 
Table 1. Steady-state kinetic parameters for dTTP incorporation of WT and mutant RTs. $^{\text {a }}$

\begin{tabular}{cccc}
\hline Enzyme & $\begin{array}{c}\boldsymbol{k}_{\text {cat }} \\
\left(\mathbf{m i n}^{-1}\right)\end{array}$ & $\begin{array}{c}\boldsymbol{K}_{\mathbf{m}} \\
(\boldsymbol{\mu M})\end{array}$ & $\begin{array}{c}\boldsymbol{k}_{\mathbf{c a t}} / \boldsymbol{K}_{\mathbf{m}} \\
\left(\boldsymbol{\mu} \mathbf{M}^{-\mathbf{1}} \mathbf{m i n}^{-\mathbf{1}}\right)\end{array}$ \\
\hline $\mathbf{W T}$ & $3.71 \pm 0.08$ & $0.0579 \pm 0.009$ & $64.07 \pm 10.05$ \\
$\mathbf{V 7 5 A}$ & $4.30 \pm 0.18$ & $0.156 \pm 0.038$ & $27.56 \pm 6.81$ \\
$\mathbf{V 7 5 F}$ & $4.87 \pm 0.15$ & $0.219 \pm 0.045$ & $22.23 \pm 4.62$ \\
$\mathbf{V 7 5 I}$ & $4.10 \pm 0.15$ & $0.153 \pm 0.045$ & $26.80 \pm 7.94$ \\
$\mathbf{V 7 5 L}$ & $4.67 \pm 0.21$ & $0.153 \pm 0.041$ & $30.52 \pm 8.29$ \\
$\mathbf{V 7 5 M}$ & $3.72 \pm 0.06$ & $0.115 \pm 0.012$ & $32.35 \pm 3.41$ \\
$\mathbf{V 7 5 S}$ & $5.49 \pm 0.21$ & $0.133 \pm 0.034$ & $41.28 \pm 10.67$ \\
$\mathbf{V 7 5 T}$ & $5.29 \pm 0.19$ & $0.168 \pm 0.043$ & $31.49 \pm 8.14$ \\
\hline
\end{tabular}

${ }^{a}$ D2-47/PG5-25 was used as the substrate. Data shown are the mean values \pm standard deviation, obtained from a non-linear least squares fit of the kinetics data to the Michaelis-Menten equation, of a representative experiment. Each of the experiments was performed independently at least twice. Inter-assay variability was below $20 \%$. 
Table 2. Steady-state misinsertion fidelity of WT and mutant RTs, as obtained using the template primer D2-47/PG5-25. ${ }^{\text {a }}$

\begin{tabular}{|c|c|c|c|c|c|}
\hline Enzyme & Nucleotide & $\begin{array}{c}k_{\mathrm{cat}} \\
\left(\mathrm{min}^{-1}\right)\end{array}$ & $\begin{array}{c}K_{\mathrm{m}} \\
(\mu \mathrm{M})\end{array}$ & $\begin{array}{c}k_{\text {cat }} / K_{\mathrm{m}} \\
\left(\mu \mathrm{M}^{-1} \mathrm{~min}^{-1}\right)\end{array}$ & $\begin{array}{c}\text { Misinsertion ratio } \\
f_{\text {ins }} b\end{array}$ \\
\hline \multirow[t]{3}{*}{ WT } & $\begin{array}{l}\text { dTTP } \\
\text { dCTP }\end{array}$ & $\begin{array}{l}3.71 \pm 0.08 \\
1.50 \pm 0.09\end{array}$ & $\begin{array}{c}0.0579 \pm 0.009 \\
755 \pm 135\end{array}$ & $\begin{array}{c}64.07 \pm 10.05 \\
(1.99 \pm 0.37) \times 10^{-3}\end{array}$ & $3.10 \times 10^{-5}$ \\
\hline & dGTP & $1.54 \pm 0.11$ & $542 \pm 136$ & $(2.84 \pm 0.74) \times 10^{-3}$ & $4.43 \times 10^{-5}$ \\
\hline & dATP & $(7.3 \pm 0.9) \times 10^{-3}$ & $\mathrm{ND}^{\mathrm{c}}$ & ND & ND \\
\hline \multirow{3}{*}{ V75A } & dCTP & $1.49 \pm 0.10$ & $298 \pm 72$ & $(5.00 \pm 1.25) \times 10^{-3}$ & $1.81 \times 10^{-4}$ \\
\hline & dGTP & $1.19 \pm 0.08$ & $305 \pm 97$ & $(3.90 \pm 1.27) \times 10^{-3}$ & $1.41 \times 10^{-4}$ \\
\hline & dATP & $(11.1 \pm 0.6) \times 10^{-3}$ & ND & ND & ND \\
\hline \multirow[t]{2}{*}{ V75F } & dTTP & $4.87 \pm 0.15$ & $0.219 \pm 0.045$ & $22.23 \pm 4.62$ & \\
\hline & dCTP & $0.85 \pm 0.08$ & $711 \pm 292$ & $(1.19 \pm 0.50) \times 10^{-3}$ & $5.35 \times 10^{-5}$ \\
\hline \multirow{3}{*}{ V75I } & dCTP & $1.30 \pm 0.25$ & $882 \pm 145$ & $(1.47 \pm 0.37) \times 10^{-3}$ & $5.48 \times 10^{-5}$ \\
\hline & dGTP & $2.10 \pm 0.43$ & $808 \pm 146$ & $(2.59 \pm 0.71) \times 10^{-3}$ & $9.66 \times 10^{-5}$ \\
\hline & dATP & $(5.8 \pm 0.9) \times 10^{-3}$ & ND & ND & ND \\
\hline
\end{tabular}

${ }^{\mathrm{a}}$ After formation of the RT-DNA/DNA complex, D2-47/PG5-25 elongation reactions were incubated at $37^{\circ} \mathrm{C}$ for $20 \mathrm{~s}$ for $\mathrm{dTTP}, 45-90 \mathrm{~s}$ for $\mathrm{dCTP}$ and dGTP, and $60 \mathrm{~min}$ for dATP. Data shown are the mean values \pm S.D., obtained from a nonlinear least-squares fit of the kinetics data to the Michaelis-Menten equation, of a representative experiment. Each of the assays was performed independently at least three times. Inter-assay variability of the kinetic parameters was below $20 \%$.

${ }^{\mathrm{b}} f_{\text {ins }}=\left[k_{\text {cat }}(\right.$ incorrect $) / K_{\mathrm{m}}($ incorrect $\left.)\right] /\left[k_{\mathrm{cat}}(\right.$ correct $) / K_{\mathrm{m}}($ correct $\left.)\right]$, where incorrect nucleotides were dCTP, dGTP, or dATP, while the correct nucletotide was dTTP.

${ }^{\mathrm{c}} \mathrm{ND}$, not determined. 
Table 3. Steady-state mispair extension fidelity of WT and mutant RTs, as obtained using template-primer D2-47/PG5-25. ${ }^{\text {a }}$

\begin{tabular}{|c|c|c|c|c|c|}
\hline Enzyme & $\begin{array}{l}\text { Base pair at } \\
\text { the 3' end }\end{array}$ & $\begin{array}{c}k_{\text {cat }} \\
\left(\mathrm{min}^{-1}\right)\end{array}$ & $\begin{array}{c}K_{\mathrm{m}} \\
(\mu \mathrm{M})\end{array}$ & $\begin{array}{c}k_{\text {cat }} / K_{\mathrm{m}} \\
\left(\mu \mathrm{M}^{-1} \mathrm{~min}^{-1}\right)\end{array}$ & $\begin{array}{c}\text { Mismatch extension ratio } \\
f_{\text {ext }}^{c}\end{array}$ \\
\hline \multirow[t]{2}{*}{ WT } & $\begin{array}{l}A: C \\
A: G\end{array}$ & $\begin{array}{c}4.41 \pm 0.12 \\
0.113 \pm 0.007\end{array}$ & $\begin{array}{l}2.77 \pm 0.46 \\
75.8 \pm 20.1\end{array}$ & $\begin{array}{c}1.592 \pm 0.268 \\
(1.49 \pm 0.40) \times 10^{-3}\end{array}$ & $\begin{array}{c}0.025 \\
2.32 \times 10^{-5}\end{array}$ \\
\hline & A:A & $0.081 \pm 0.005$ & $62.7 \pm 14.4$ & $(1.29 \pm 0.31) \times 10^{-3}$ & $2.01 \times 10^{-5}$ \\
\hline \multirow[t]{2}{*}{ V75A } & $A: C$ & $4.35 \pm 0.14$ & $5.67 \pm 0.72$ & $0.767 \pm 0.100$ & 0.028 \\
\hline & A:A & $0.071 \pm 0.004$ & $51.3 \pm 12.1$ & $(1.38 \pm 0.34) \times 10^{-3}$ & $5.00 \times 10^{-5}$ \\
\hline \multirow[t]{3}{*}{ V75F } & $\mathrm{A}: \mathrm{C}$ & $5.90 \pm 0.37$ & $37.6 \pm 8.7$ & $0.156 \pm 0.038$ & $7.02 \times 10^{-3}$ \\
\hline & $A: G$ & $0.051 \pm 0.005$ & $368 \pm 131$ & $(1.39 \pm 0.51) \times 10^{-4}$ & $6.25 \times 10^{-6}$ \\
\hline & A:A & $0.041 \pm 0.003$ & $282 \pm 74$ & $(1.45 \pm 0.39) \times 10^{-4}$ & $6.52 \times 10^{-6}$ \\
\hline
\end{tabular}

${ }^{a}$ After formation of the RT-DNA/DNA complex, mispair extension reactions were incubated at $37^{\circ} \mathrm{C}$ for $20 \mathrm{~s}$ for the elongation of $\mathrm{A}$ : $\mathrm{T}$ and $\mathrm{A}$ : $\mathrm{C}$ mispairs, and 15-40 min for A:G and A:A mispairs. In all cases, we measured the incorporation of T opposite A at position +1 . Data shown are the mean values \pm S.D., obtained from a nonlinear least-squares fit of the kinetics data to the Michaelis-Menten equation, of a representative experiment. Each of the assays was performed independently at least three times. Inter-assay variability of the kinetic parameters was below 20 $\%$.

${ }^{\mathrm{a}}$ The first base corresponds to the template and the second to the primer.

${ }^{\mathrm{b}} f_{\mathrm{ext}}=\left[k_{\mathrm{cat}}(\right.$ mismatched $) / K_{\mathrm{m}}($ mismatched $\left.)\right] /\left[k_{\mathrm{cat}}(\right.$ matched $) / K_{\mathrm{m}}($ matched $\left.)\right]$ 
Table 4. Pre-steady-state kinetic parameters of WT and mutants RTs for misincorporation. ${ }^{a}$

\begin{tabular}{|c|c|c|c|c|c|}
\hline Enzyme & Nucleotide & $\begin{array}{l}k_{\text {pol }} \\
\left(\mathbf{s}^{-1}\right)\end{array}$ & $\begin{array}{c}K_{\mathrm{d}} \\
(\mu \mathrm{M})\end{array}$ & $\begin{array}{c}k_{\text {pol }} / K_{\mathrm{d}} \\
\left(\mu \mathbf{M}^{-1} \mathbf{s}^{-1}\right)\end{array}$ & $\begin{array}{c}\text { Misinsertion ratio } \\
f_{\text {ins }}\end{array}$ \\
\hline \multirow[t]{3}{*}{ WT } & dTTP & $11.57 \pm 0.49$ & $13.40 \pm 1.88$ & $0.863 \pm 0.126$ & \\
\hline & $\mathrm{dCTP}$ & $0.291 \pm 0.052$ & $7645 \pm 2959$ & $(3.80 \pm 1.62) \times 10^{-5}$ & $4.40 \times 10^{-5}$ \\
\hline & dGTP & $0.289 \pm 0.032$ & $3435 \pm 1099$ & $(8.40 \pm 2.84) \times 10^{-5}$ & $9.73 \times 10^{-5}$ \\
\hline \multirow[t]{3}{*}{ V75A } & dTTP & $15.23 \pm 1.45$ & $16.30 \pm 4.96$ & $0.934 \pm 0.298$ & \\
\hline & $\mathrm{dCTP}$ & $0.178 \pm 0.009$ & $4170 \pm 734$ & $(4.26 \pm 0.78) \times 10^{-5}$ & $4.58 \times 10^{-5}$ \\
\hline & dGTP & $0.153 \pm 0.008$ & $2271 \pm 446$ & $(6.74 \pm 1.37) \times 10^{-5}$ & $7.22 \times 10^{-5}$ \\
\hline \multirow[t]{3}{*}{ V75F } & dTTP & $8.36 \pm 0.65$ & $33.25 \pm 6.91$ & $0.251 \pm 0.056$ & \\
\hline & $\mathrm{dCTP}$ & $0.057 \pm 0.002$ & $7067 \pm 594$ & $(8.06 \pm 0.73) \times 10^{-6}$ & $3.22 \times 10^{-5}$ \\
\hline & dGTP & $0.135 \pm 0.025$ & $11006 \pm 3537$ & $(1.23 \pm 0.45) \times 10^{-5}$ & $4.90 \times 10^{-5}$ \\
\hline \multirow[t]{3}{*}{ V75I } & dTTP & $7.86 \pm 0.88$ & $12.07 \pm 4.64$ & $0.651 \pm 0.261$ & \\
\hline & $\mathrm{dCTP}$ & $0.175 \pm 0.023$ & $16116 \pm 3666$ & $(1.08 \pm 0.29) \times 10^{-5}$ & $1.66 \times 10^{-5}$ \\
\hline & dGTP & $0.408 \pm 0.041$ & $12741 \pm 1970$ & $(3.20 \pm 0.59) \times 10^{-5}$ & $4.92 \times 10^{-5}$ \\
\hline
\end{tabular}

${ }^{\text {a }}$ The template-primer 21P/31T was used as the substrate. Data shown are the mean values \pm standard deviation of a representative experiment. Each of the assays was performed independently at least twice. Inter-assay variability was below $20 \%$.

${ }^{\mathrm{b}} f_{\text {ins }}=\left[k_{\mathrm{pol}}(\right.$ incorrect $) / K_{\mathrm{d}}($ incorrect $\left.)\right] /\left[k_{\mathrm{pol}}(\right.$ correct $) / K_{\mathrm{d}}($ correct $\left.)\right]$, where incorrect nucleotides were dCTP or dGTP, while the correct nucleotide was dTTP. 
Table 5. Pre-steady-state kinetic parameters of WT and mutants RTs for mispair extension. ${ }^{\mathrm{a}}$

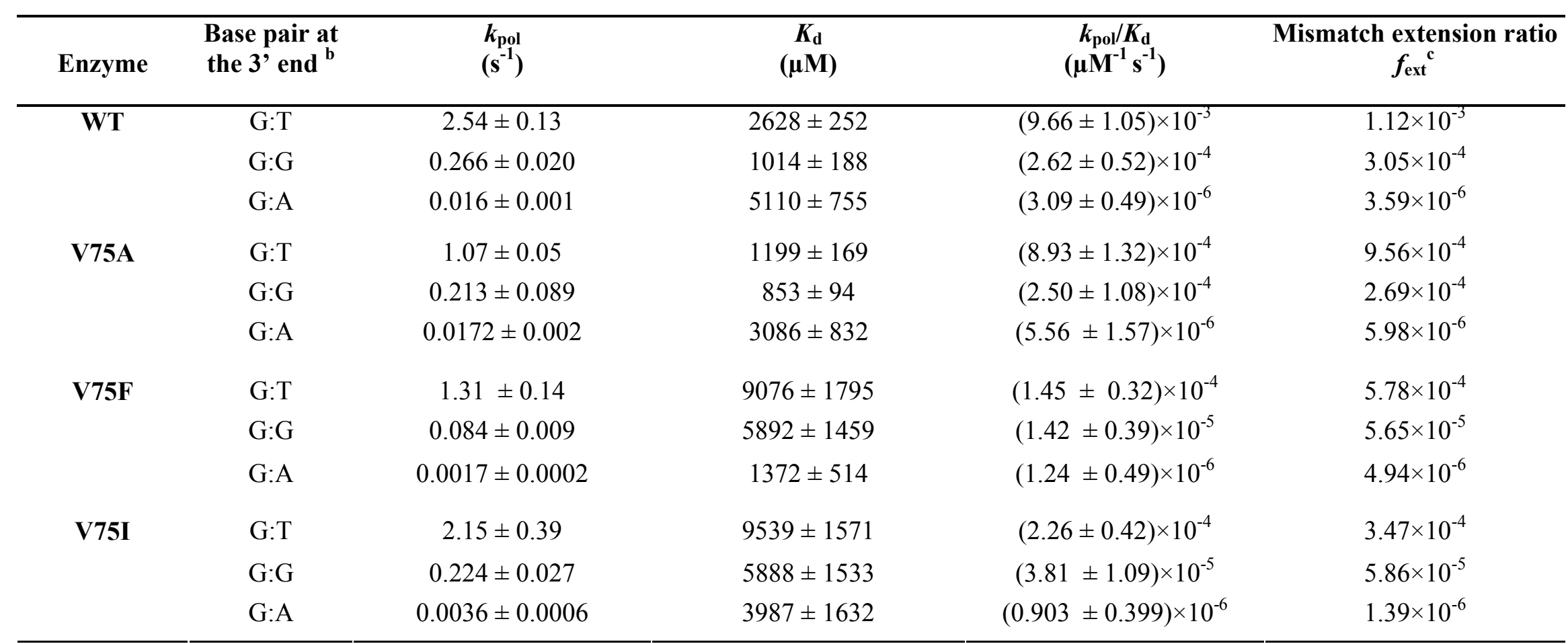

${ }^{\text {a }}$ The template-primer 21P/31T was used as the substrate. Data shown are the mean values \pm standard deviation of a representative experiment. Each of the assays was performed independently at least twice. Inter-assay variability was below $20 \%$.

${ }^{\mathrm{b}}$ The first base corresponds to the template and the second to the primer.

${ }^{\mathrm{c}} f_{\mathrm{ext}}=\left[k_{\mathrm{pol}}(\right.$ mismatched $) / K_{\mathrm{d}}($ mismatched $\left.)\right] /\left[k_{\mathrm{pol}}(\right.$ matched $) / K_{\mathrm{d}}($ matched $\left.)\right]$. 
Table 6. Accuracy of WT and mutants RTs in M13mp2 lacZ $\alpha$ forward and reversion mutation assays.

\begin{tabular}{lcccc}
\hline Enzyme & Total plaques & $\begin{array}{c}\text { Mutant } \\
\text { plaques }\end{array}$ & $\begin{array}{c}\text { Mutant } \\
\text { frequency } \\
\left(\times \mathbf{1 0}^{-4}\right)\end{array}$ & $\begin{array}{c}\text { Fidelity } \\
\text { (fold } \\
\text { increase) }\end{array}$ \\
\hline M13mp2 lacZa Forward Mutation Assay & & & \\
\hline WT & 6736 & 139 & 206 & - \\
V75A & 5271 & 148 & 281 & 0.7 \\
V75F & 6157 & 69 & 112 & 1.8 \\
V75I & 6033 & 42 & 69.6 & 3.0 \\
\hline M13mp2 lacZa Reversion Mutation Assay & & & - \\
\hline WT & 1292640 & 35 & 27 & 3.5 \\
V75I & 4059250 & 32 & 7.8 & \\
\hline
\end{tabular}

${ }^{a}$ As a control, nucleotide sequencing of the entire 361-base pair lacZ $\alpha$ gene obtained from M13mp2 DNA isolated from 5 mutant colonies of each DNA synthesis reaction was performed. All colonies contained single mutations within the lac $Z$ target that produced gene inactivation. Background mutant frequency for this assay was estimated to be around $5 \times 10^{-4}$. 
Click here to download high resolution image
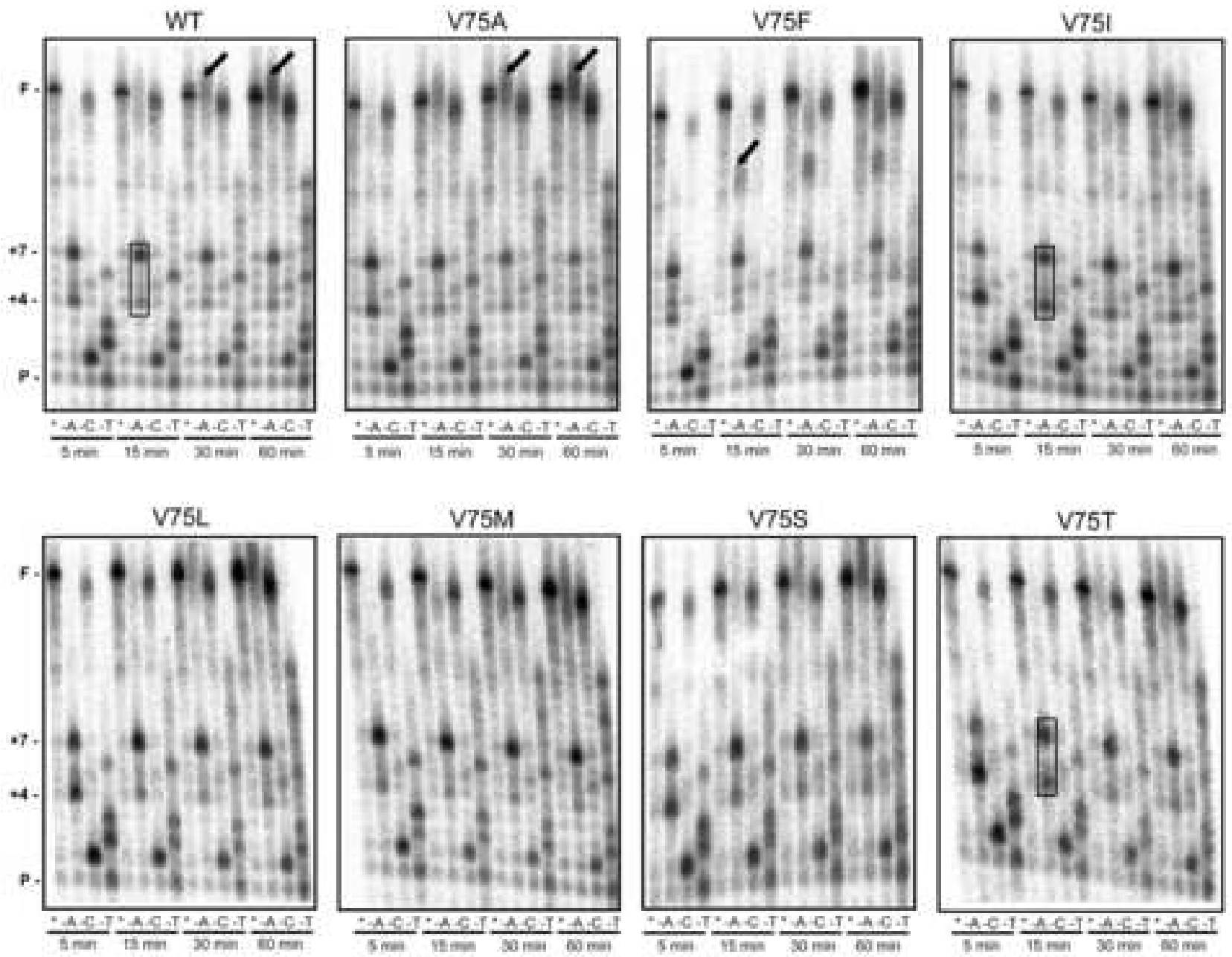

$02-47$ 5 DOATTMATMANTAOTAMGAATGTATAGCCCTACCAOCATTCTgG $y$ POS - 25

y TACATATCQOOATDOTCGTARGACC 5 
Click here to download high resolution image

(a)

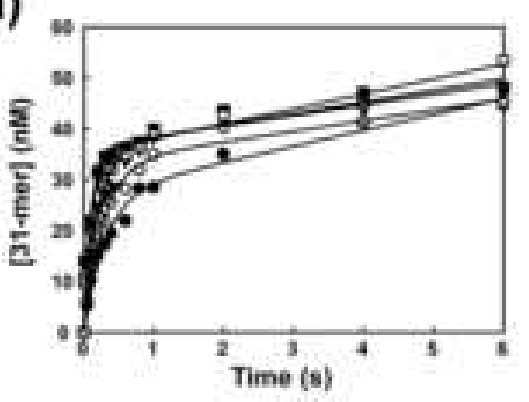

dTTP
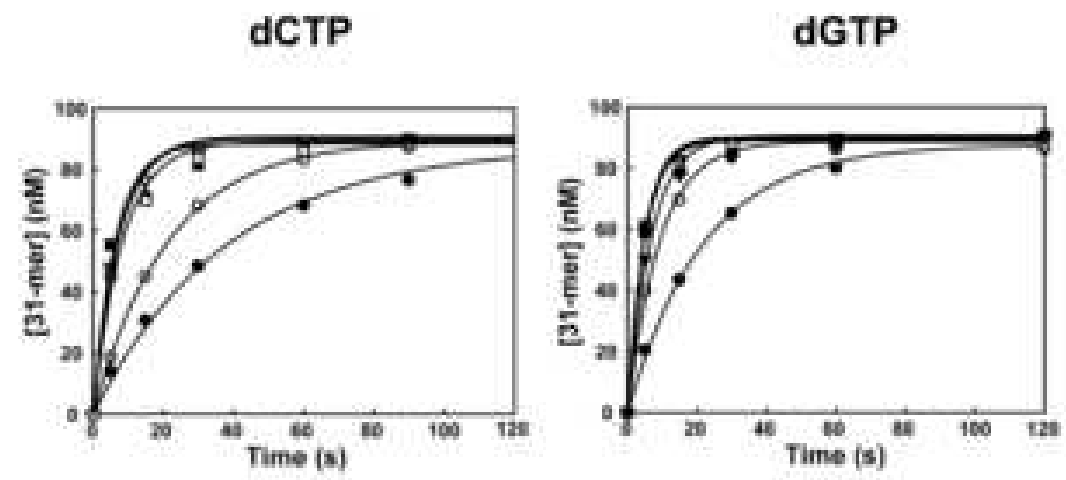

(b)
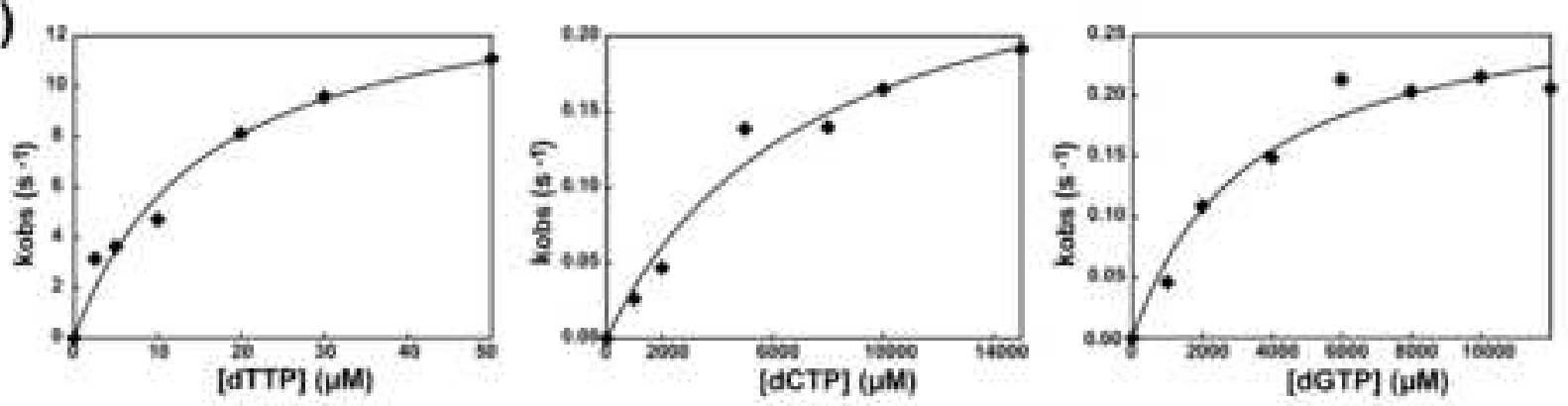

(c)
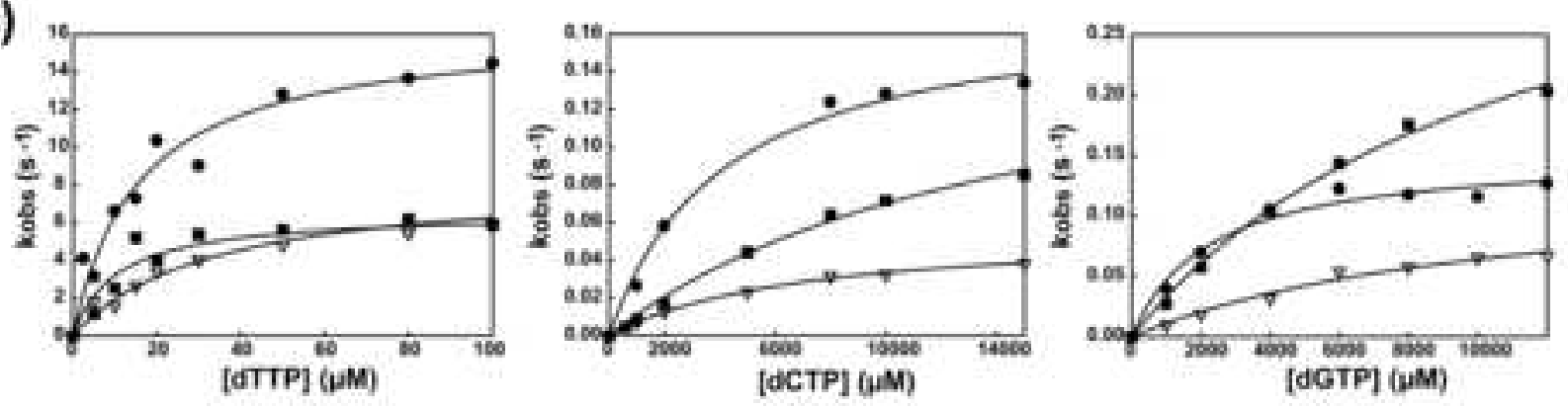
Click here to download high resolution image

$\mathbf{G : T}$

(a)
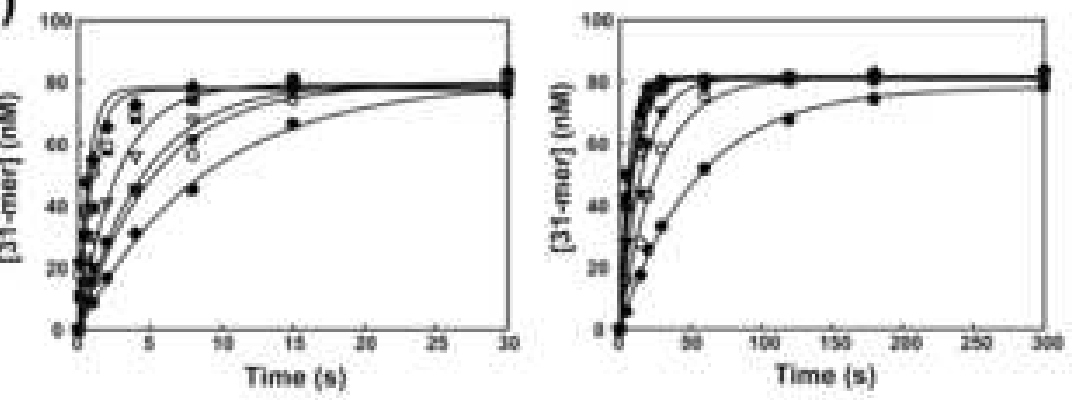

(b)
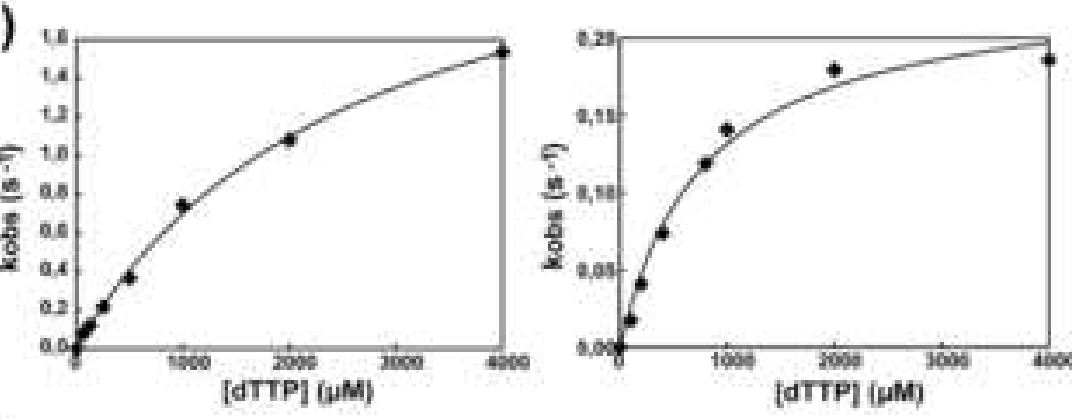

(c)
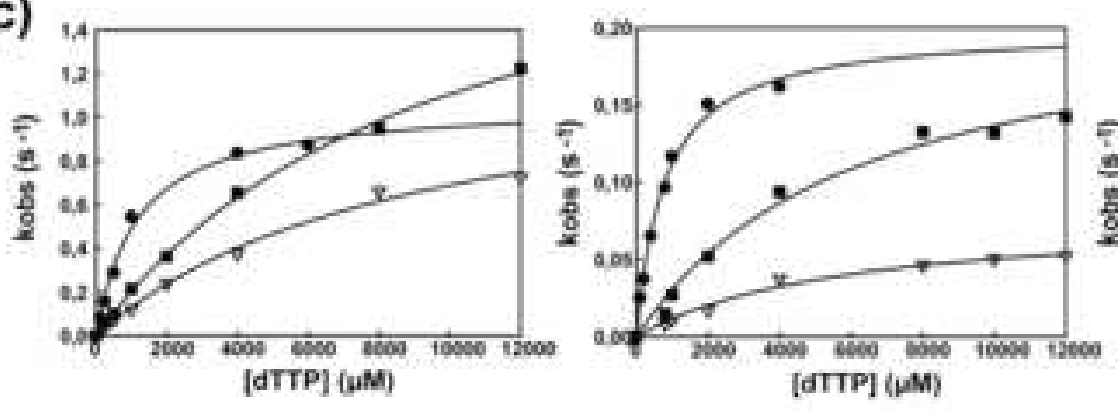
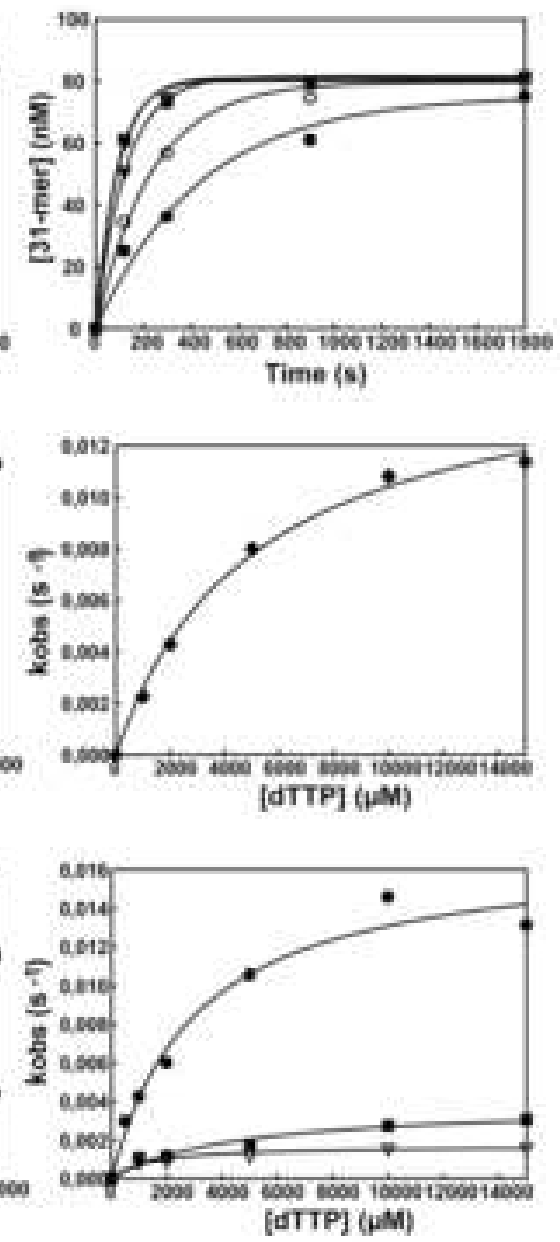

G:G 
Figure 4
Click here to download high resolution image

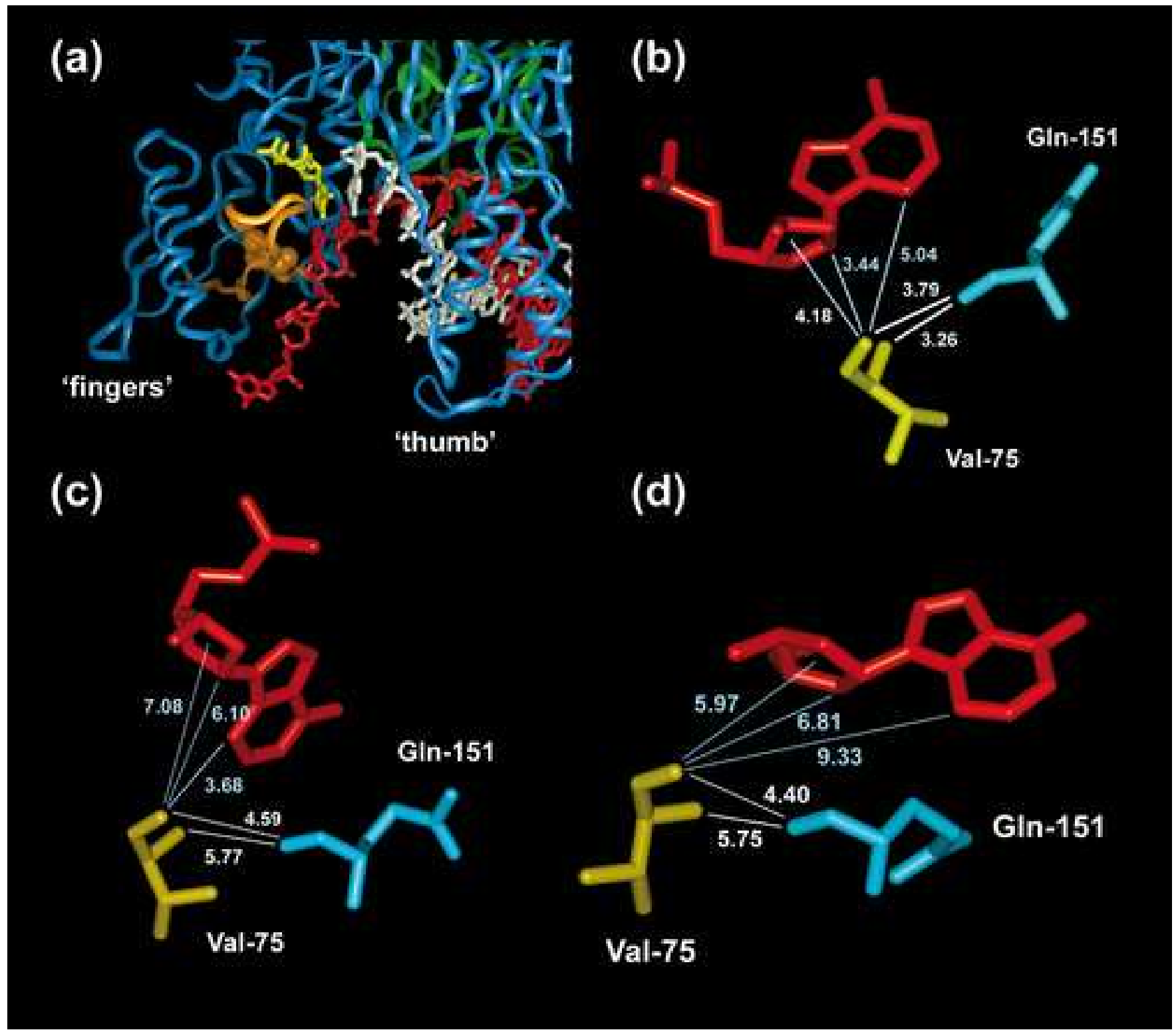


Figure 5
Click here to download high resolution image

(a)
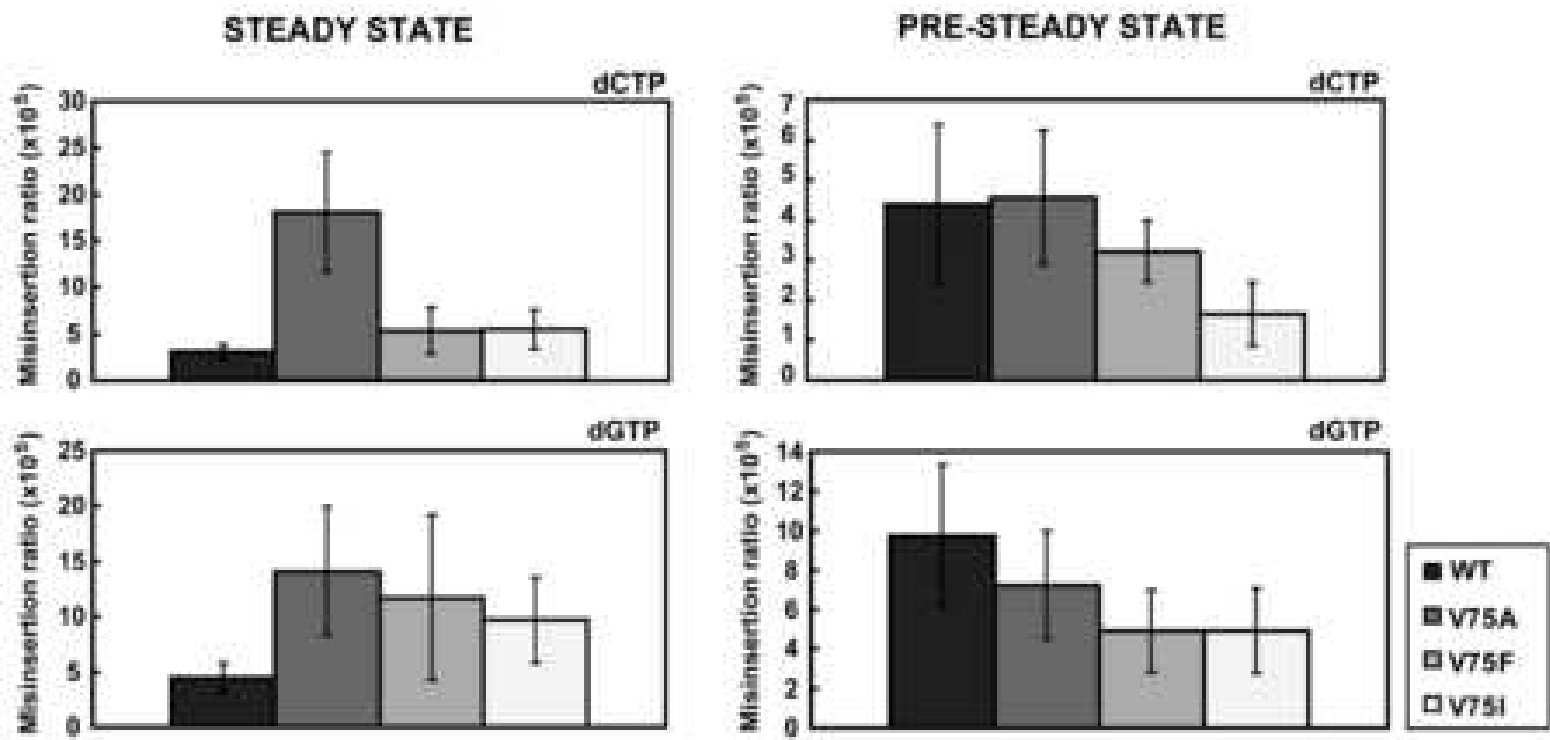

(b)

STEADY STATE
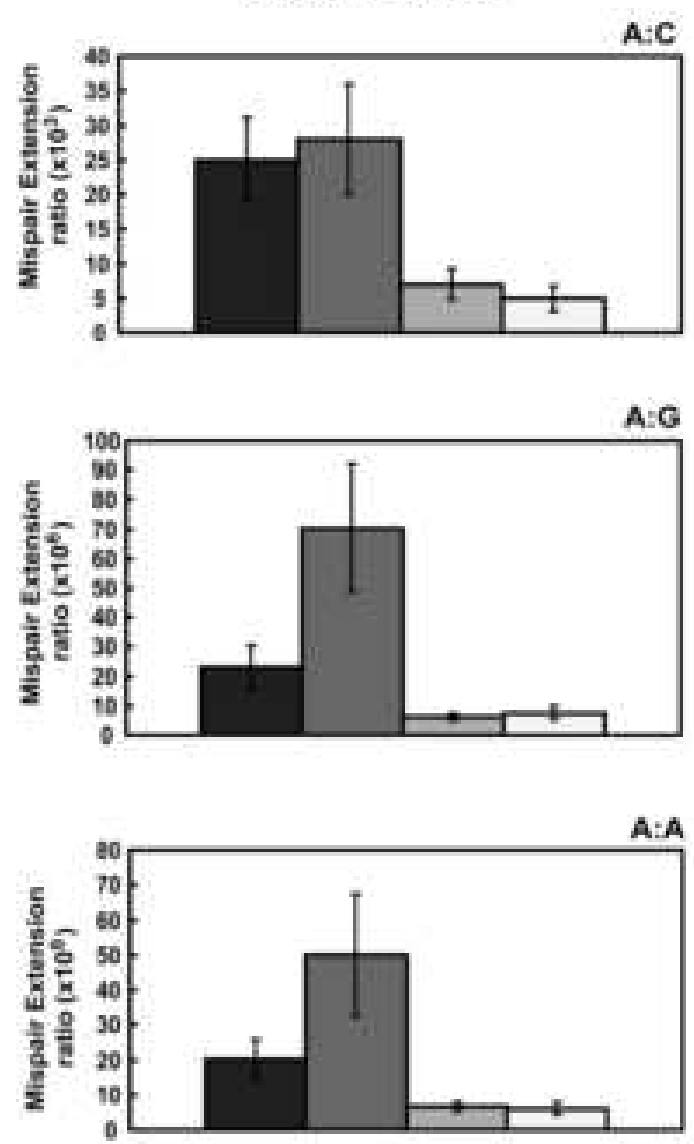

PRE-STEADY STATE
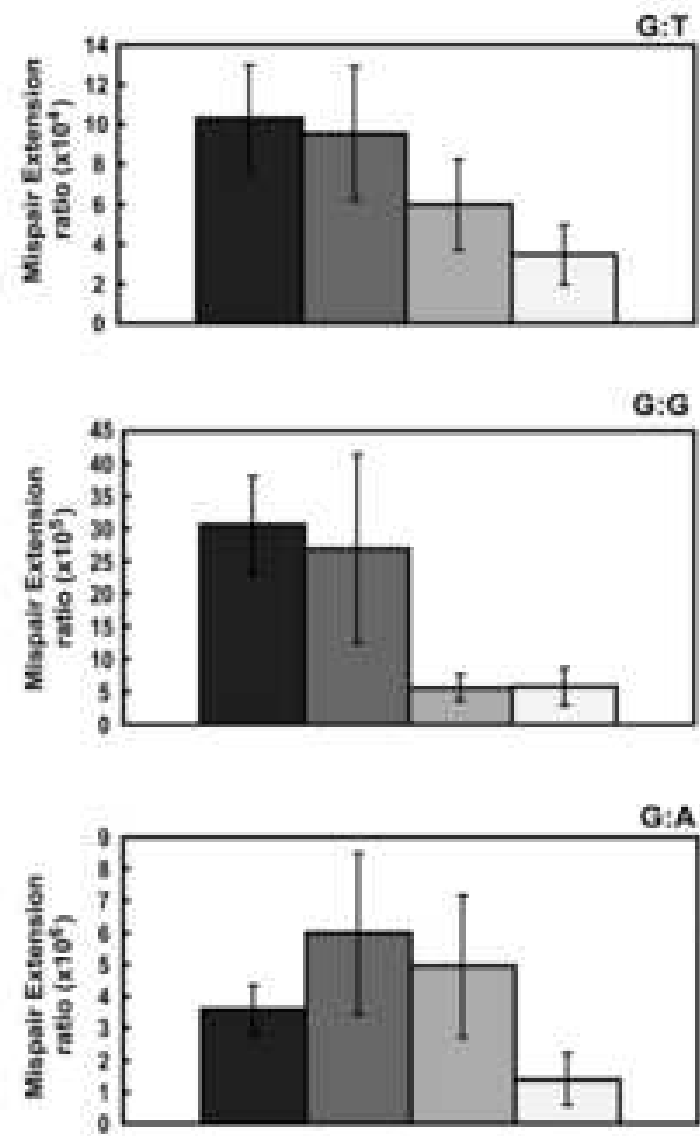

- $W T$

a V75A

aV75F

aV751 